\title{
Forest fluxes and mortality response to drought: model description (ORCHIDEE-CAN-NHA, r7236) and evaluation at the Caxiuanã drought experiment
}

Yitong $\mathrm{Yao}^{1 *}$, Emilie Joetzjer ${ }^{2 *}$, Philippe Ciais ${ }^{1}$, Nicolas Viovy ${ }^{1}$, Fabio Cresto Aleina ${ }^{1}$, Jerome Chave ${ }^{3}$,

${ }^{1}$ Laboratoire des Sciences du Climat et de l'Environnement, LSCE/IPSL, CEA-CNRS-UVSQ, Université Paris-Saclay, Gifsur-Yvette, 91191, France

${ }^{2}$ Centre National de Recherche Meteorologique, Unite mixte de recherche 3589 Meteo-France/CNRS, 42 Avenue Gaspard 10 Coriolis, Toulouse, 31100, France

${ }^{3}$ Laboratoire Evolution et Diversité Biologique UMR 5174 CNRS, IRD, Université Paul Sabatier, Toulouse, 31062, France

${ }^{4}$ Department of Ecology and Evolutionary Biology, University of California Los Angeles, Los Angeles, California, 90095, USA

${ }^{5}$ Department of Viticulture \& Enology, University of California, Davis, California, 95616, USA

$15 \quad{ }^{6}$ Research School of Biology, Australian National University, Canberra, ACT 2601 Australia

${ }^{7}$ CICERO Centre for International Climate and Environmental Research, Oslo, Norway

${ }^{8}$ Faculty of Science, Vrije Universiteit Amsterdam, Netherlands

* These authors contributed equally to this work.

Correspondence to: Yitong Yao (yitong.yao@1sce.ipsl.fr)

Abstract. Extreme drought events in Amazon forests are expected to become more frequent and more intense with climate change, threatening ecosystem function and carbon balance. Yet large uncertainties exist on the resilience of this ecosystem to drought. A better quantification of tree hydraulics and mortality processes is needed to anticipate future drought effects on Amazon forests. Most state-of-the-art dynamic global vegetation models are relatively poor in their mechanistic description of these complex processes. Here, we implement a mechanistic plant hydraulic module within the ORCHIDEE-CAN-NHA r7236 land surface model to simulate the percentage loss of conductance (PLC) and changes in water storage among organs via a representation of the water potentials and vertical water flows along the continuum from soil to roots, stems and leaves. The model was evaluated against observed seasonal variability in stand-scale sap flow, soil moisture and productivity under both control and drought setups at the Caxiuanã throughfall exclusion field experiment in eastern Amazonia between 2001 and 2008. A relationship between PLC and tree mortality is built in the model from two empirical parameters, the cumulated drought exposure duration that triggers mortality, and the mortality fraction in each day exceeding the exposure. Our model captures the large biomass drop in the year 2005 observed four years after throughfall reduction, and produces comparable annual tree mortality rates with observation over the study period. Our hydraulic architecture module provides promising 
35 avenues for future research in assimilating experimental data to parameterize mortality due to drought-induced xylem dysfunction. We also highlight that species-based (isohydric or anisohydric) hydraulic traits should be further tested to generalize the model performance in predicting the drought risks.

\section{Introduction}

Drought-induced forest mortality events are projected to become more frequent and intense under current climate trends

40 (Allen et al., 2015) and may threaten vegetation carbon sinks, as well as biophysical climate regulation by forests (Allen et al., 2010;McDowell et al., 2018). Amazonian rainforests hold the largest forest biomass carbon stock on Earth as one of the most important components of the global carbon balance. In the last 15-20 years Amazonia has been heavily affected by concurrent drought at intervals of 5-6 years (Lewis et al., 2011;Phillips et al., 2009; Yang et al., 2018). A persistent increase of biomass mortality and levelling-off of stand-level growth rate from forest inventory plots suggest a decrease of net biomass accumulation rate over the past 30 years (Brienen et al., 2015). The predicted intensification of droughts for future climate change scenarios may continue to cause increased tree mortality across large areas (Duffy et al., 2015), and exacerbate the likelihood of exceeding a tipping point for regional carbon stocks (Nobre and Borma, 2009). Yet, great uncertainties prevent understanding and quantification of tree mortality, given the high diversity of tree species with different resistance and resilience to drought. Ecosystem models are especially challenged to simulate climate induced mortality at individual and stand level, given the lack of field studies providing long-term data for both biometric measurements and observations of soil and canopy physical climate variables leading to water stress and impairment of tree function. Local ecosystem models with a simulation of individual tree growth and death are computationally expensive, require a large number of parameters per species, and are generally less developed for simulating the soil water dynamics and surface energy budget. Upscaling of these models is also challenging (Maréchaux et al., 2021) and to our knowledge, few land surface models have included climate induced

55 mortality beyond that arising from crowding and tree longevity related mortality for large regions (Adams et al., 2017;Delbart et al., 2010; Powell et al., 2013). On the other hand, land surface models, part of Earth System Models, have advanced capabilities to simulate water and energy fluxes between forests and the atmosphere, but usually have rather simple representations of biomass carbon dynamics, and many of them do not explicitly resolve climate-induced mortality processes. A mechanistic representation and prediction of the Amazon forest response to drought in global land surface models is thus an important priority for research.

Early vegetation models parameterized mortality through indicators of competition-induced self-thinning and /or threshold of growth vigor (Adams et al., 2013;Zhu et al., 2015;McDowell et al., 2011), which ignored the mortality related to extreme events such as drought. Improving mortality representation requires more robust physiological processes embedded in models that couple water, carbon and energy fluxes (Gustafson and Sturtevant, 2013). Recent advances have been made for improved resolution of the mechanisms by which trees die from drought. Two non-exclusive physiological mechanisms have 
https://doi.org/10.5194/gmd-2021-362

Preprint. Discussion started: 20 December 2021

(c) Author(s) 2021. CC BY 4.0 License.

\section{(c) (i)}

been proposed: hydraulic failure and carbon starvation (Choat et al., 2018;McDowell et al., 2018;Meir et al., 2015). Hydraulic failure occurs when the tension within the xylem vessels is so high that it causes air-seeded embolism, which impedes water transport. If embolism exceeds a tree dependent survival threshold (Cochard and Delzon, 2013), individual tree dieback may occur, possibly with some lag in case of insufficient repair capabilities to restore upward water transport. Carbon starvation during drought is expected to occur from prolonged stomatal closure causing reduced photosynthetic assimilation, resulting in a drawdown and possible exhaustion of nonstructural carbohydrate reserves (NSC) (Hartmann, 2015; Signori-Müller et al., 2021). Also, embolized vessels may be detrimental to the carbon assimilation processes, so that hydraulic failure and carbon starvation are coupled together (McDowell et al., 2018). Many studies have tried to discern the respective contributions of the two mechanisms in tree wilting during drought (Rowland et al., 2015; Yoshimura et al., 2016). After 15-years of experimental throughfall exclusion in a forest in the Amazon, Rowland et al. (2015) found that hydraulic failure was most closely associated with tree mortality under the drier condition, and that there was no distinct difference in NSC concentration between droughted and non-droughted trees, although seasonal differences were observed. Here, we will build on this early understanding of drought-induced impacts in the Amazon and present a model where hydraulic failure is considered to be the dominant risk factor for tree mortality, but we recognize the importance of carbon starvation and also investigate primary production and labile carbon changes in the simulations.

Efforts have been made toward accounting for physically-based water transport in land surface models, implemented through regulation of stomatal behavior, and the explicit simulation of water transport across the soil, root, stem, leaves and atmosphere continuum following a gradient of water potential and organ-specific conductivity parameters. The Ecosystem Demography model optimized the marginal increase of net carbon assimilation per unit of water loss within the soil-plantatmosphere continuum to simulate a realistic stomatal conductance (Xu et al., 2016). Given the benefit-cost tradeoff between photosynthetic carbon gain and hydraulics uplift of water, Sperry et al. (2017) modeled stomatal behavior by maximizing the instantaneous difference between photosynthetic gain and the proximity to hydraulic failure. The target of such stomatal optimization schemes varies from carbon gains (Dewar et al., 2018), water use efficiency (Bonan et al., 2014) to profit maximization of the difference between carbon gain and hydraulic cost (Sabot et al., 2020), or optimization was performed using a linear function of water potential (Eller et al., 2018) or xylem conductance (Eller et al., 2020). In addition to the optimization of stomatal control, key features of water potential along the soil-plant-atmosphere continuum are also introduced in some models to describe plant hydraulic responses. Papastefanou et al. (2020) modeled plant hydraulics starting from leaf water potential in consideration of iso-hydricity among different hydraulics strategies. De Kauwe et al. (2020) incorporated the plant hydraulic module 'Desica' into the CABLE land surface model, which simulated water flows and water potential through the soil-plant-atmosphere continuum following Xu et al. (2016). Kennedy et al. (2019) generated new configurations of prognostic vegetation water potential at the root, stem and leaf levels and based plant water stress on the metrics of leaf water potential in the community land model version 5a. Explicit representations of plant hydraulics in process-based models advance our knowledge of the plant responses to drought (Hendrik and Maxime, 2017). However, in terms of how tree 
https://doi.org/10.5194/gmd-2021-362

Preprint. Discussion started: 20 December 2021

(c) Author(s) 2021. CC BY 4.0 License.

\section{(c) (i)}

mortality responds to future climate scenarios, research gaps still remain in the specific thresholds of hydraulics failure beyond which drought stress induces tree mortality (Anderegg, 2015; Choat, 2013;Hammond et al., 2019), which limits the development and testing of hydraulic failure mechanisms coupled to mortality in Amazonian rainforests.

Identifying a specific threshold for hydraulic failure associated with a given mortality likelihood remains challenging (Choat et al., 2018). Drought indices related to climate have already been tested in this context and were found to be species and trait dependent. Anderegg et al. (2015) found that hydraulic conductivity of aspen dropped rapidly when accumulated climatic water deficit from 2000-2013 exceeds almost $5300 \mathrm{~mm}$ from break-point regression analysis. Relative water content derived from vegetation optical depth also contains the signal of such a threshold relationship with drought-driven mortality rates (Rao et al., 2019). The percentage of loss in conductivity (PLC) has also been found to be an appropriate metric for assessment of hydraulic dysfunction (Adams et al., 2017), and has been linked experimentally to plant mortality (Brodribb and Cochard, 2009; Liu et al., 2021a;Urli et al., 2013). Liu et al. (2021a) fitted relationships between simulated PLC and observed mortality rate across investigated sites via multiple regression, and used this formula for the prediction of mortality. Brodribb and Cochard (2009) found that the maximum survivable water stress in conifer species was a $95 \%$ loss in leaf

115 conductance. For five angiosperm tree species in Europe, Urli et al. (2013) found that the embolism threshold was closer to the water potential at $88 \%$ of conductance loss. Plant volumetric water content also shows a threshold-type response empirically related to mortality risk, with an inflection point at $47 \%$ of volumetric content (Sapes et al., 2019). Thus, the lethal point can differ among tree species, and presumably strongly in tropical forests in which different species vary widely over hydraulic traits (Bittencourt et al., 2020; Rowland et al., 2015). This variation needs to be considered in hydraulic modelling.

Currently, only a few studies have integrated plant hydraulic failure as a process in a global land surface model and parameterized mortality as a consequence. In this study, we implement a mechanistic hydraulic architecture modeling of the water transport in the continuum from soil to atmosphere in the ORCHIDEE-CAN model. We refer to this New Hydraulic Architecture module as "NHA" that is, ORCHIDEE-CAN-NHA. We describe three developments and their evaluation against

125 field measurements for control and experimental throughfall conditions, in aspects of soil and plant water variables, and biometric variables such as tree growth and mortality, at the Amazon tropical forest site of Caxiuanã (Fisher et al., 2006;Meir et al., 2018). Firstly, we describe the development of the new hydraulic architecture model. Then we carry out site-level simulations and evaluate the model performance in aspects of seasonal variability in transpiration, soil moisture and productivity against experimental control and drought observations. Thirdly with the simulation of dynamic water potential,

130 water transport, and conductance, the model is extended to define a mortality risk from continuous high loss of stem conductance from cavitation. In this part, we bridge the gap between reaching a stem conductance threshold corresponding to a high loss of conductance and mortality risk. Finally, we compare the modeled mortality in different circumference classes to verify whether our improved model can capture the observed size-related mortality distribution, with trees being first rather insensitive to drought during the first years, after which larger trees are affected by dieback. 


\subsection{Model description and simulation protocols}

\subsubsection{The starting point: ORCHIDEE-CAN r2290}

The model version taken as the starting point for development in this study is ORCHIDEE-CAN (r2290), a branch of the ORCHIDEE land surface model. ORCHIDEE is a physical process-based model, which can simulate the energy, water, and carbon fluxes between land surfaces and the atmosphere. The SECHIBA module corresponds to faster processes, such as exchange of water and energy as well as photosynthesis between land and the atmosphere in half hour time interval. The carbon module (STOMATE) simulates soil processes (soil decomposition, heterotrophic respiration, soil organic carbon dynamics) at the half-hourly time step and vegetation carbon cycle processes at daily intervals, including carbon allocation, vegetation mortality and recruitment, phenology, litter fall. The development of this branch of the ORCHIDEE model focuses on improving the capability of the ORCHIDEE model to simulate the biogeochemical and biophysical effects of forest management and includes allometric-based allocations of carbon to different pools, a simple plant hydraulic structure (see below) as well as an albedo scheme that in part depends on canopy structure (Naudts et al., 2015). One of its new features is the way the vegetation is discretized; a dynamic canopy structure is simulated by considering a user-defined number of circumference classes ( $\mathrm{n}=20$ in this study) and an empirical rule reflecting intra-tree competition that downscales canopy level GPP into the different circumference classes, which feedback on light interception and mortality through self-thinning. Background mortality comes from the reciprocal of a constant residence time. Climate based mortality, e.g. from drought has not been modeled yet using this system.

\subsubsection{Hydraulic architecture representation in ORCHIDEE-CAN}

In ORCHIDEE-CAN r2290 (Naudts et al., 2015), the representation of water stress is realized through a constraint based on the amount of water that plants can transport from soil to their leaves. This constrained transpiration supply equals the quotient between the water potential gradient from soil to leaves, and a total hydraulic resistance of leaf, stem and root. In this framework, the leaf water potential is fixed to a constant value for each plant functional type (PFT), with specific minimum value (-2.2 MPa for tropical evergreen forests, Hickler et al. (2006). The soil water potential in the root zone is calculated by

160 adding a tuned scaling factor, accounting for soil-root resistance and other missing processes, to the sum of the soil water potential (calculated from soil moisture and van Genuchten parameters, Van Genuchten (1980) weighted by a proportion of root mass in each soil layer. Such hard modulator can sometimes lead to unrealistic soil water potential in the root zone (Joetzjer et al., under review). The prescribed vegetation distribution is used to constrain this modulator to minimize model bias (Naudts et al., 2015). During the simulation, transpiration is co-limited by the energy budget providing a transpiration demand, and the transpiration water supply limited by transport from soil to leaves. When the potential transpiration constrained by the energy budget is higher than the transpiration supply, real transpiration is limited to the physically plausible water supply. Then the 
https://doi.org/10.5194/gmd-2021-362

Preprint. Discussion started: 20 December 2021

(c) Author(s) 2021. CC BY 4.0 License.

(c) (i)

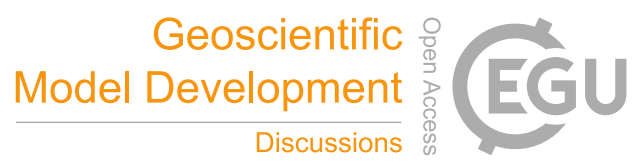

energy budget and photosynthesis-related processes are recalculated. It should be noted that the root and leaf resistance parameters in ORCHIDEE-CAN depend only on conductivity and biomass (root mass for root, LAI for leaf) and do not respond to hydrological conditions directly. Only the stem resistance related to xylem conductivity is dynamic and changes as a function of the soil water potential in the root zone. The schematic framework of the ORCHIDEE-CAN model is illustrated in Figure 1a. This architecture is not completely mechanistic, given the tuned factor on top of soil water potential, the fixed leaf water potential values and the conductivities affected solely by organ mass. Therefore, further developments of the hydraulic architecture scheme were performed and presented here.

\section{2.1.3 Dynamic root scheme in ORCHIDEE-CAN-RS}

To increase the reliability of soil water potential simulations in root zone $\left(\Psi_{\text {soil-root }}\right)$, Joetzjer et al (under review) improved this part of the model (flowchart in Figure 1b, ORCHIDEE-CAN-RS). $\Psi_{\text {soil-root }}$ integrated $\Psi_{\text {soil }}$ in the root zone vertically, i.e. $\Psi_{\text {soil }}$ in the root zone is now weighted by the maximum amount of water that can be absorbed by roots in each soil layer $\left(E_{\max }\right)$, which depends on a soil-to-root resistance and on a prescribed minimum root water potential (-3 MPa in this study) below which no more water in a given soil layer can be drawn into the plant. The soil-to-root resistance accounts for the water transport path from soil to root surface. With this scheme, the plant will dynamically use deep layer soil moisture when the surface soil desiccates, so that this process allows to sustain more transpiration from deeper layers during dry periods. Although Joetzjer et al (under review) solved the problem of tuned modulator imposed on $\Psi_{\text {soil-root }}$ by adding a parameterization of the soil-to-root resistance, a more integral mechanistic structure of water transport from soil to leaf remains to be done to enable a dynamic connection between soil and leaf as well as corresponded simulations during drought events. $\Psi_{\text {soil-root }}$ is calculated separately for different cohorts, since we assume taller trees have deeper roots and can reach water stored in deeper layers. For example, we assume that the largest cohort can take water from all 12 soil layers while the smallest cohort can only take water in shallow layer.

\subsubsection{Hydraulic scheme development and implementation in ORCHIDEE-CAN-NHA r7236}

Figure 1c presents the schematic diagram of the new hydraulic architecture in ORCHIDEE-CAN-NHA. Besides the water transport driven by vertical water pressure difference, the water flow to / from organ-specific water storage at time $t$ is explicitly modeled based on capacitances and water potential differences between time $t$ and $t-1$. For each organ, the water supply should meet its water demand. For example, water demand at leaf level is parameterized as the transpiration supply. Water supply to leaf is composed by water transport from stem minus the water charge or plus the discharge from the leaf water storage pool. The water budget of the leaves is calculated first, in order to determine how much water has to be drawn up from the other connected upstream organs. It should be noted that the new hydraulic mechanism is imposed on 20 circumference classes, separately. The detailed description of new mechanistic hydraulic processes is given below. 


\subsubsection{Water storage calculation}

The Supply-Demand framework is solved at leaf, stem and root, separately. We assume that during the first time step, all water potentials in different organs are the same (Eq. 1).

$\Psi_{\text {leaf }, t}=\Psi_{\text {stem }, t}=\Psi_{\text {root }, t}=\Psi_{\text {soil-root }, t}$

Water storage in the different organs is calculated with organ-specific capacitance values (unit: mmol):

$m_{\text {leaf }, \text { max }}=\frac{b_{\text {leaf }}}{L D M C}-b_{\text {leaf }}$

$m_{\text {leaf }, t}=m_{\text {leaf }, \max }+C_{\text {leaf }} \psi_{\text {leaf }, t} L A$

Where $C_{\text {leaf }}$ is relative leaf capacitance in unit of $\mathrm{mmol} \mathrm{m}^{-2} \mathrm{MPa}^{-1}, L D M C$ the leaf dry matter content, $b_{\text {leaf }}$ is the dry leaf biomass. $L A$ is total leaf area. Maximum water storage in leaf $\left(m_{\text {leaf,max }}\right)$ is generated by leaf fresh mass minus dry mass. $m_{\text {leaf }, t}$ is leaf water storage at time $\mathrm{t}$.

$m_{\text {sap, } \max }=v_{\text {stem }} W C$

$m_{\text {sap }, t}=m_{\text {sap }, \max }+C_{\text {stem }} \psi_{\text {stem }, t} v_{\text {stem }}$

$v_{\text {stem }}=\pi\left(\frac{d b h}{2}\right)^{2} h$

Where $C_{\text {stem }}$ is sapwood capacitance, $\mathrm{h}$ tree height in $\mathrm{m}, v_{\text {stem }}$ is proportional to the volume of tree stem in $\mathrm{m}^{3}$. WC is the amount of water (mmol) per unit volume of sapwood. $m_{s a p, \max }$ and $m_{s a p, t}$ are maximum sapwood water storage and sapwood water storage at time $\mathrm{t}$, respectively. $d b h$ is the diameter at breast height.

$m_{\text {root,max }}=b_{\text {root }}$ root $_{w c}(7)$

$b_{\text {root }}=v_{\text {stem }} \times W D \times$ ratio $_{\text {root: }}$ shoot

$v_{\text {root }}=\frac{b_{\text {root }}}{\rho_{\text {root }}}$

$m_{\text {root }, t}=m_{\text {root }, \max }+c_{\text {root }} \psi_{\text {root }, t} v_{\text {root }}$

Where root $_{w c}$ indicates the amount of water $(\mathrm{mmol})$ stored in per gram of root mass. WD is aboveground wood density. $v_{\text {root }}$ is root volume. ratio root:shoot is root to shoot ratio. $b_{\text {root }}$ is root mass. $\rho_{\text {root }}$ is root density. $m_{\text {root, max }}$ and $m_{\text {root }, t}$ are maximum root water storage and root water storage at time $t$, respectively. $c_{\text {root }}$ is root capacitance.

\subsubsection{Hydraulic conductance calculation}

Hydraulic conductance per unit of leaf area in leaf, sapwood and root at time $\mathrm{t}\left(k_{\text {leaf }, t}, k_{\text {stem }, t}, k_{\text {root }, t}\right)$ are calculated with 225 sigmoidal relationships, based on their real-time water potential and a maximum conductance. $\psi_{50, \text { organ }}$ denotes the water potential when $50 \%$ conductance lost. $e^{a_{\text {organ }}}$ describes the sensitivity of conductance to changes in water potential around $\psi_{50, \text { organ }}$. An example for how these two shape parameters affecting sapwood conductance is shown in Figure 2 for the stem organ. 
where $k_{\text {leaf, } t}$ and $k_{\text {leaf,max }}$ are leaf conductance at time $\mathrm{t}$ and maximum leaf conductance, respectively.

$k_{\text {stem }, t}=\frac{k_{\text {stem }, \max }}{1+\exp \left(a_{\text {stem }} \times\left(\varphi_{\text {stem }, t}-\varphi_{50, \text { stem }}\right)\right)}$

where $k_{\text {stem }, t}$ and $k_{\text {stem,max }}$ are stem sapwood conductance at time $\mathrm{t}$ and maximum stem sapwood conductance, respectively.

$k_{\text {root }, t}=\frac{k_{\text {root }, \max }}{1+\exp \left(a_{\text {root }} \times\left(\varphi_{\text {root }, t}-\varphi_{50, \text { root }}\right)\right)}$

235 where $k_{\text {root, } t}$ and $k_{\text {root,max }}$ are root conductance at time $t$ and maximum root conductance, respectively.

The conductance of the upper part of the tree (leaf plus upper part of stem) and lower part of the tree (lower part of stem plus root) are calculated following Eq. 14-15. These two conductances will be used to calculate the water flow from stem to leaf, and root to stem later separately.

$k_{\text {upper }, t}=\frac{1}{\frac{1}{k_{\text {leaf }, t}}+\frac{1}{2 k_{\text {stem }, t}}}$

$k_{\text {trunk }, t}=\frac{1}{\frac{1}{2 k_{\text {root }, t}}+\frac{1}{2 k_{\text {stem }, t}}}$

\subsubsection{Water transport pathway simulation}

We assume that for leaves, transpiration supply is based on the water input transported from the stem minus the water charge/discharge from the leaf water storage pool (Eq. 16).

$245 T_{\text {supply }}=J_{\text {leaf }, t+1}-W_{\text {leaf }, t+1}$

Where $J_{\text {leaf }, t+l}$ is the flux of water transported vertically to leaf from stem sapwood (unit: mmol) and $W_{\text {leaf }, t+l}$ the change in leaf water storage. A positive value of $W_{\text {leaf }, t+1}$ means that the leaf was charged with water during hydraulic recovery, and negative means it was reduced by evapotranspiration. At leaf level, the target is to solve for the leaf water potentials that minimize the difference between water demand and supply (Eq. 17).

$\Delta=\left(J_{\text {leaf }, t+1}-W_{\text {leaf }, t+1}\right)-T_{\text {demand }}$

Similarly, at stem level, the target is to minimize the difference between water demand at stem and water supply to the stem (Eq. 18).

$\Delta=\left(J_{\text {stem }, t+1}-W_{\text {stem }, t+1}\right)-J_{\text {leaf }, t+1}$

$J_{\text {stem }, t+1}$ is the water transported vertically from root to stem. $W_{\text {stem }, t+l}$ the change in stem water storage. After solving leaf-level

255 target, $\mathrm{J}_{\text {leaf }, \mathrm{t}+1}$ is known, which is the water demand at stem.

At root level, the target is to minimize the difference between water demand at root and water supply to root (Eq. 19)

$\Delta=\left(J_{\text {root }, t+1}-W_{\text {root }, t+1}\right)-J_{\text {stem }, t+1}$

$J_{r o o t, t+l}$ is the water transported from soil in root zone to root. $W_{r o o t, t+l}$ is the change in root water storage. After solving stem- 
level target, $J_{\text {stem }, t+1}$ is known, which is the water demand at root. The detailed calculations of these water flow variables are explained below in the order of leaf, stem and root.

\section{a. Leaf transport}

The water movement into the leaf through the hydraulic pathway is calculated as

$J_{\text {leaf }, t+1}=\left(\psi_{\text {stem }, t}-\psi_{\text {leaf }, t+1}-\psi_{h / 2}\right) k_{\text {upper }, t+1} L A$

$W_{\text {leaf }, t+1}=c_{\text {leaf }}\left(\psi_{\text {leaf }, t+1}-\psi_{\text {leaf }, t}\right) L A$

A positive $W_{\text {leaf } t+1}$ means an increase in leaf water storage and vice versa.

$\Psi_{h / 2}$ indicates how much water potential gradient is needed to pull water against gravity up to the height $(h)$ of the tree from position of $1 / 2$ tree height (middle of stem).

We calculate $J_{\text {leaf }, t+1}$ and $W_{\text {leaf }, t+1}$ using an optimization procedure i.e. we start by assuming $\psi_{\text {leaf }, t+1}=\psi_{\text {stem, } t}$ and progressively decrease $\psi_{\text {leaf }, t+1}$ until the difference between leaf water supply and demand is close to zero (Eq. 22).

$\Delta=T_{\text {supply }}-T_{\text {demand }}$

$T_{\text {demand }}$ is related to stomatal conductance, $V P D$ and total leaf area (Eq. 23), where stomatal conductance varies with $\Psi_{\text {leaf }}$ (Eq. 24).

$T_{\text {demand }}=g_{s} \frac{V P D}{\text { atm }} L A$

$275 g_{s}=\frac{g_{\max } \frac{L \times R a d}{L \times R a d+L_{k}}}{1+e^{a_{g s}\left(\psi_{l e a f, t}-\psi_{50, g s}\right)}}+g_{\min }$

$g_{s}, g_{\max }$ and $g_{\min }$ are in unit of $\mathrm{mmol} \mathrm{m} \mathrm{m}^{-2} \mathrm{~s}^{-1} . V P D$ is in unit of $\mathrm{kPa}$. LA is total leaf area.

atm is standard atmospheric pressure $(101.3 \mathrm{kPa}) \cdot \frac{L \times R a d}{L \times R a d+L_{k}}$ is the function of short-wave radiation (Rad), which is used to ensure $g_{s}$ at night is close to zero. Minimum leaf water potential in this study is set to $-3.0 \mathrm{MPa}$ to avoid unrealistic value (Fisher et al., 2006).

280 We verified that our simulated $g_{s}$ with the parameters values from Table A1 are of similar magnitude than in the SPA model of Fisher et al (2007) at Caxiuana, which was developed independently from ORCHIDEE (Figure S1). Further, in order to show that our model parameters can be used to simulate $g_{s}$ at other rainforest sites, we collected $g_{s}$ observations (at leaf scale) from two rainforests in French Guiana and Peru from Lin et al (2015) and tested our model against these observations. Figure S2 shows that our simulated $g_{s}$ values fall in the range observed at these two sites.

\section{b. Stem transport}

Next, we know that the water demand at stem is the amount of water transported from stem to leaf, $J_{\text {leaf }, t+l}$. We can now use the same procedure to calculate the $\Psi_{\text {stem, } t+l}$ that produces the expected $J_{\text {leaf },+1}$, and how much of that transport is from storage and from the roots through the vertical hydraulic pathway. 
$J_{\text {stem }, t+1}=\left(\psi_{\text {root }, t}-\psi_{\text {stem }, t+1}-\psi_{h / 2}\right) k_{\text {trunk }, t+1} L A$

$W_{\text {stem }, t+1}=c_{\text {stem }}\left(\psi_{\text {stem }, t+1}-\psi_{\text {stem }, t}\right) v_{\text {stem }}$

$S_{\text {stem }, t+1}=J_{\text {stem }, t+1}-W_{\text {stem }, t+1}$

$\Delta=S_{\text {stem }, t+1}-J_{\text {leaf }, t+1}$

$S_{\text {stem }, t+I}$ is the water supply to stem. $J_{\text {leaf }, t+I}$ is the water demand at stem. Then we try to solve the $\Psi_{\text {stem }, t+I}$ to minimize the

295 difference between $J_{\text {leaf }, t+I}$ and $S_{\text {stem }, t+l}$ (Eqs. 27-28).

\section{c. Root transport}

The same procedure is also carried out for root. The total flow out of the root is equal to $J_{\text {stem }, t+l}$. We calculate root water transport according to the following equations:

$J_{\text {root }, t+1}=\left(\psi_{\text {soil-root }, t}-\psi_{\text {root }, t+1}\right) 2 k_{\text {root }, t+1} L A$

$W_{\text {root }, t+1}=c_{\text {root }}\left(\psi_{\text {root }, t+1}-\psi_{\text {root }, t}\right) v_{\text {root }}(30)$

$S_{\text {root }, t+1}=J_{\text {root }, t+1}-W_{\text {root }, t+1}$

$\Delta=\mathrm{S}_{\text {root }, t+1}-J_{\text {stem, } t+1}$

$J_{\text {stem }, t+l}$ is the water demand at root. $S_{\text {root }, t+l}$ is the water supply to root. Then we try to solve the $\Psi_{\text {root }, t+l}$ to minimize the difference between $J_{\text {stem }, t+l}$ and $S_{\text {root }, t+l}$ (Eq. 31-32). The '2' in Eq. 29 means half of the root is accounted ( $\left.\frac{1}{\frac{1}{2 \times k_{\text {root }}}}\right)$ here since the other half of the root is considered in $k_{\text {trunk, }}$.

We assume that water does not travel in reverse, leaving the roots and going into the soil. We also impose a limit on vertical water flow to non-negative values.

\subsubsection{Update water storage pools}

After the simulation of water transport, we use the $\mathrm{W}_{\mathrm{t}+1}$ values to update the water storage in each organ.

$$
\begin{aligned}
& m_{\text {leaf }, t+1}=m_{\text {leaf }, t}+W_{\text {leaf }, t+1} \\
& m_{\text {stem }, t+1}=m_{\text {stem }, t}+W_{\text {stem }, t+1} \\
& m_{\text {root }, t+1}=m_{\text {root }, t}+W_{\text {root }, t+1}
\end{aligned}
$$

All above calculation processes are carried out for 20 circumference classes, separately. The parameters used in the new hydraulic architecture are summarized in Table A1. 


\subsubsection{Parameterization of tree mortality related to drought}

Since trees can endure drought conditions and do not die after one or two days of low stem water potential or water shortage (Brodribb et al., 2020), we defined an exposure threshold dessiccation time to trigger mortality. Continuous exposure to a high percentage loss of conductance forebodes tree mortality, therefore a decision rule was set with two empirical parameters, a drought mortality exposure threshold (in days) and a mortality fraction of trees each time (in $\%$ of all trees that die). When PLC $>50 \%$ condition lasts for more than 15 continuous days, we assume that a fraction of $0.6 \%$ of all the trees in each size cohort are killed. These two parameters are tuned according to the observed annual mortality rates. It should be noted that a cohort model represents all the trees in a grid cell as one average individual, thus an absolute mortality threshold would kill them all on the same day. Hence we impose a fractional mortality to capture the variability in mortality drivers and processes within each cohort. We also consider that a very short wetting break during a drought condition would not necessarily act to reverse embolism and thus the tree's exposure to mortality. Here the minimum threshold for a continuous wetting break (PLC $<50 \%$ ) to reset the exposure to zero is set to 5 days. The annual mortality rate equals to the number of dead trees per year divided by the number of trees alive in the beginning of this year.

Finally, following ORCHIDEE-CAN-RS, the recruitment rate is determined by LAI (Joetzjer et al., under review). When LAI decreases during drought, the recruitment rate will increase correspondingly since recruitment is parameterized as function of LAI. The new outputs from ORCHIDEE-CAN-NHA are listed in Table A2.

\section{$335 \quad$ 2.1.6 Biomass growth and loss}

$\Delta$ biomass $=$ growth - loss (36)

As ORCHIDEE does not account for BVOC emissions, root exudation and C-subsidies to mycorrhizae, biomass growth is simulated as the residual of GPP minus autotrophic respiration. Biomass loss comes from three processes in ORCHIDEE: turnover (loss of leaves and fine roots), self-thinning and climate-induced morality, that is, drought for this study. It should be noted that, in ORCHIDEE-CAN, when the number of individuals falls below a parameterized threshold, self-thinning does not happen and individuals grow without competing with each other.

\subsection{Site description}

The study site is a tropical lowland rainforest located in the Caxiuanã National forest, state of Para, north-east of Brazil $345\left(1^{\circ} 43^{\prime} \mathrm{S}, 51^{\circ} 27^{\prime} \mathrm{W}\right)$. Annual rainfall in this site is $2000-2500 \mathrm{~mm}$ with dry season spanning from July to November (monthly rainfall $<100 \mathrm{~mm}$ ). A throughfall exclusion experiment (TFE) started in the end of dry season in 2001, where $50 \%$ of canopy throughfall is excluded by plastic roof at the height of 1-2m above the ground (Fisher et al., 2007; Meir et al., 2018). At the same time, a 1-ha control plot is also set without any manipulation. 
From published literature (Carswell et al., 2002; da Costa et al., 2010; Fisher et al., 2007;Rowland et al., 2015), we collected observation data as validation for model simulation, including transpiration data, soil moisture data, annual mortality rate, annual biomass density, GPP and respiration components (Table 1). We also used output from the SPA (soil-plantatmosphere) model with parameters measured for the Caxiuanã experiment. SPA is a multilayer soil-vegetation-atmosphere transfer model, which has been parameterized upon such drought affected ecosystems (Fisher et al., 2007). We included simulated GPP output from SPA for model evaluation under TFE since eddy covariance flux measurements can only be used in model-data comparison under CTL.

Table 1 Collected observation data used for validation of process-based model simulation.

\begin{tabular}{cccc}
\hline Variables & Period & Time step & References \\
\hline Transpiration & $2001-2003$ & Daily & Fisher et al (2007) \\
Soil moisture & $2001-2004$ & Monthly & Fisher et al (2007) \\
Biomass density & $2001-2008$ & Annual & $\begin{array}{c}\text { Observation from Rowland } \text { et al (2015) } \\
\text { and da Costa } \text { et al (2010) }\end{array}$ \\
GPP & Daily & $\begin{array}{c}\text { SPA model : Fisher } \text { et al (2007), } \\
\text { flux data: Carswell } \text { et al. (2002) }\end{array}$ \\
Mortality rate & Annual & da Costa et al (2010); \\
& $2001-2003$ & Rowland et al (2015) \\
\hline
\end{tabular}

\subsection{Simulation protocols}

We performed three simulations at site-level for Caxiuanã to compare the hydraulic architecture from each model version. Specifically, we tested the model performance under two setups, the control (CTL) and the throughfall exclusion experiments (TFE). In the model, TFE is reproduced by keeping only $50 \%$ of the rainfall of CTL with all else being the same as CTL (Fisher et al., 2007). It should be noted that such rainfall cut is a simplification since in reality, a plastic panel is used to exclude $50 \%$ of throughfall. We run $250 \mathrm{yr}$ spin-up by cycling over climate forcing data over 2001 to 2008 with constant $\mathrm{CO}_{2}$ concentration of $380 \mathrm{ppm}$ to get the preliminary state of carbon pools and water flow at the beginning of 2001. Two former model versions, and our new developments are integrated as below. We compare ORCHIDEE-CAN-RS and ORCHIDEE-CAN-NHA to see the improvements brought by the new hydraulic architecture. It should be noted that all these three simulations are realized through several flags to switch on/off some functionality. 
(1) ORCHIDEE-CAN with the original simple hydraulic module setup.

(2) ORCHIDEE-CAN-RS, which adds new dynamic soil-root scheme on top of (1)

(3) ORCHIDEE-CAN-NHA, with the new mechanistic hydraulics on top of (2).

\subsection{Statistical tools}

We used the R programming environment and statistical packages (version 3.5.0; R Core Team 2019) for all data processing and analysis. Package ncdf4 v1.17 (Pierce, 2019) is used to handle files in NetCDF format from model outputs. Package fields v10.3 (Nychka D, 2020) is used in water potential plotting.

\section{Results}

\subsection{Model evaluation against observation}

\subsubsection{Evapotranspiration and soil moisture}

Under the control (CTL) condition, the model developed here (ORCHIDEE-CAN-NHA) agreed well with the sap flow observations from well-watered periods but underestimated sap flow in the dry season. The dry season points in Figure 3 are those with a water deficit of up to $-3 \mathrm{~mm}_{\text {day }}{ }^{-1}$ (monthly precipitation below evapotranspiration). Regressing modeled transpiration with sap flow observations, we found that the model better represents the month-to-month seasonal variability under CTL than TFE ( $\mathrm{R}=0.73$ in CTL v.s. $\mathrm{R}=0.51$ in TFE). Under the TFE condition, the model overestimated transpiration in both the wet and dry seasons, with a positive bias increasing at water deficits typically below $-2 \mathrm{~mm} / \mathrm{d}$ (Figure 3 ). Simulation by ORCHIDEE-CAN-RS also showed such a positive bias (Figure S3). This positive model bias was mainly contributed by the simulation in 2002 when the TFE experiment was installed by the end of 2001. The transpiration supply did not show water limitation on transpiration under TFE until the end of the dry season in 2002 (Figure S4).

The partitioning of evapotranspiration (ET) was compared between CTL and TFE. Under the CTL condition, the modeled partition of evapotranspiration (ET) into transpiration (T), intercepted canopy water or dew re-evaporation (CE), and bare soil evaporation (E) is shown in Figure S5, with the ratio (T/ET) being around 0.62 in the wet season, and 0.75 in the dry season. Under TFE, the difference of T/ET between the dry and the wet season increased (wet: 0.63 vs. dry: 0.84 ). Specifically, under CTL, the daily mean transpiration can reach more than $4 \mathrm{~mm} / \mathrm{d}$ and soil evaporation accounted for $31 \%$ of total ET in the wet season. The magnitude of transpiration increased by $46 \%$ in the dry season (range: $17 \%-67 \%$ ) compared to that in wet season under CTL, which is consistent with observations ( $+44 \%$ in Fisher et al., 2007), due to higher energy supply and non-water limiting conditions. This indicated that normal conditions at this site are not very strongly limited by soil moisture during the dry season, despite recurrent deficits, as shown by the red bars on the top of Figure 4. Nevertheless, under TFE, the transpiration was lower than in CTL and encountered emerging water supply induced limitation in the dry season, with $\mathrm{T}_{\mathrm{dry}} / \mathrm{T}_{\text {wet }}$ of 1.13 
https://doi.org/10.5194/gmd-2021-362

Preprint. Discussion started: 20 December 2021

(c) Author(s) 2021. CC BY 4.0 License.

\section{(c) (i)}

over 2002-2008 (minimum $\mathrm{T}_{\text {dry }} / \mathrm{T}_{\text {wet }}$ can be 0.62 in 2005) (Figure 4). Soil evaporation also decreased a lot under TFE from wet to dry season, and the ratio (E/ET) was halved from the wet to the dry season, especially in the year 2005, 2006 and 2007 , when annual rainfall was relatively lower.

We next examined the model performance (ORCHIDEE-CAN-NHA) for reproducing the soil moisture dynamics during the observation period between 2001 and 2004. Soil moisture content (SMC) featured a pronounced seasonal decrease between wet and dry periods under CTL and TFE (Figure 5). Under CTL, in the surface soil, the model produced a small underestimation of SMC in both wet and dry seasons compared to observation. With increasing depth in the soil, this negative difference between modeled and observed SMC became more pronounced in the dry season (Figure 5). Under TFE, a similar negative difference also appeared in the dry season only, while a positive difference appeared in the wet period. Besides, under TFE, the modeled SMC was however always lower than for CTL in the surface layer, and got even more depleted in the deeper layer with the dynamic soil-root scheme, even in wet season (Figure 6), because this scheme shifts root uptake from surface to deep layers when the surface dries out compared to simulation of ORCHIDEE-CAN (Figure S6).

\subsubsection{Carbon fluxes}

GPP simulation outputs had a similar seasonality under CTL among all model versions (Figure S7). All simulations showed higher GPP in the dry season compared to the wet season under CTL (also in eddy covariance Carswell et al., 2002). When we compared GPP against the SPA model results from Fisher et al (2007) that were calibrated to best fit site-level observations, and against flux observation, we found that modeled GPP in ORCHIDEE-CAN-NHA showed a larger seasonal amplitude than that of SPA but with a similar phase (Figure 7). GPP seasonality from eddy covariance data was also in agreement with the simulation from ORCHIDEE-CAN-NHA, with a peak in the middle of the dry season. In contrast, the SPA modeled GPP decreased right from the start of the dry season. We found that the impact of TFE condition on modeled GPP was relatively small during the wet season, with a difference less than $10 \%$ in comparison with CTL (see Figure S7 for the two other versions). On the other hand, the impact of TFE during the dry season led to a pronounced decrease of GPP, like in the SPA model. In ORCHIDEE-CAN-NHA, GPP decreased only in the end of the dry season under TFE while in SPA it decreased from the beginning (Figure 7). Only after two years of drought, ORCHIDEE-CAN-NHA simulated an early decrease of GPP at the beginning of the dry season, and thus became consistent with SPA (Figure 7).

\subsection{Simulated water potential gradients along the soil to leaf continuum}

With the mechanistic hydraulic architecture of ORCHIDEE-CAN-NHA, the dynamic water potential at leaf, stem and root levels were modeled and compared with observations (Figure S8). Diurnal cycle of $\Psi_{\text {leaf }}$ was comparable between model and observations although the modeled $\Psi_{\text {leaf }}$ was less negative than the observation in the noon (Figure S8). The lowest water potential was simulated in the leaf, followed by stem, as expected. There was clear seasonal variability between wet and dry 
https://doi.org/10.5194/gmd-2021-362

Preprint. Discussion started: 20 December 2021

(c) Author(s) 2021. CC BY 4.0 License.

(c) (i)

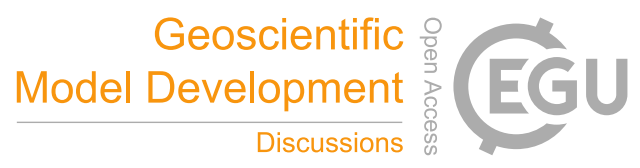

435 periods especially under TFE conditions (Figure 8). Under CTL, the water potential vertical negative gradient between leaf and root was similar between the wet and the dry season (-0.82 MPa in wet season, $-0.86 \mathrm{MPa}$ in dry season for tree cohort $\# 10$, that is in diameter of $1.15 \mathrm{~m}$; for the cohorts description see Methods); the minimum monthly mean $\Psi_{\text {leaf, }} \Psi_{\text {stem }}$ and $\Psi_{\text {root }}$ were -1.4 MPa, -1.0 MPa and -0.9 MPa in the dry season, respectively. Under TFE, $\Psi_{\text {leaf }}, \Psi_{\text {stem }}$ and $\Psi_{\text {root }}$ were prominently more negative during the dry season (-2.5 MPa, -1.8 MPa, -1.6 MPa, respectively) and the range of water potential gradients between stem and root in the dry season became a bit narrower than that in the wet season, which reflected the fact that the water flow from vertical transport is limited. With regard to the change of water storage, leaf water storage decreased continuously from wet to dry season but did not approach depletion of water storage (Figure S9). $\Psi_{\text {leaf }}$ in the dry season in year 2005 (dry season rainfall is minimum) reached its minimum during the whole simulation period under TFE. We can see that at leaf and stem levels, $\Psi_{\text {leaf }}$ and $\Psi_{\text {stem }}$ decreased slightly with the size of cohorts and they were a bit more negative in larger (taller) cohorts correspondingly (Figure 8, Figure S10). Taller trees have a longer water transport path, which means greater gravitational potential energy is needed to pull water upward (Eq. 20). Thus more negative $\Psi$ values were expected in the cicumference classes with higher trees.

\subsection{Simulated hydraulic failure}

Here, we used the simulated Percentage Loss of Conductance (PLC) in stem sapwood as an indicator of tree hydraulic failure. Under CTL, the PLC remained lower than 50\% even in dry seasons, due to weak water limitation (see soil moisture deficits in Figure 5 and water potential gradients in Figure 8). Under TFE, the PLC did not reach above 50\% in wet seasons, but in dry seasons, it increased to more than $80 \%$ especially in the (abnormally dry) year 2005 (Figure 9). Under TFE, the number of days with PLC above 50\% were 8 days, 52 days in years 2002 and 2003 respectively, and reached up to 73 days in year 2005 (cohort \#10). Besides its seasonal variability, PLC also moderately increased with the size of cohorts, denoting more severe water stress in larger / taller cohorts (Figure S11).

Next, we looked at the two variables defined to link PLC with mortality in the model: the PLC mortality exposure threshold and the mortality fraction per day of exposure (see Methods). The mortality exposure threshold represents a maximum tolerable drought duration for trees before a fraction of them die. In this study, this mortality threshold is set to consecutive 15 days when PLC stays above $50 \%$. The mortality fraction is set to a death rate of $0.6 \%$ during each day of the exposure period (no preferential rule is imposed for small or large trees). In absence of any measurement, the values of these two mortality-triggering variables were calibrated to reproduce the observed mortality in the TFE experiment. We estimated the mortality fraction by totaling the dead trees in each year and dividing this number by the initial tree density in each year. With this scheme, estimated drought-induced tree mortality rates were shown in Figure 9. The model simulated that more than $10 \%$ of trees in larger cohorts (\#12 to \#20) would be killed by the dry conditions in 2005 (Figure 9), which was a bit larger than the $7 \%$ of mortality observed in the experiment. The model simulation produced a reasonable (but slightly too large) 
https://doi.org/10.5194/gmd-2021-362

Preprint. Discussion started: 20 December 2021

(c) Author(s) 2021. CC BY 4.0 License.

(c) (i)

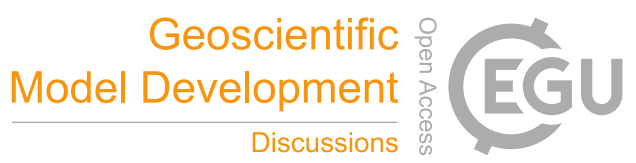

biomass mortality under TFE during 2002 to 2008 (Figure 10, Figure S12), with a modeled biomass loss ( $56 \mathrm{MgC} / \mathrm{ha}, \sim 16 \%$ of biomass in 2001) being a bit larger than observation ( $\sim 30 \mathrm{MgC} / \mathrm{ha}, \sim 12 \%$ of biomass in 2001). Figure 11 showed that under $\mathrm{CTL}$, the biomass loss due to self-thinning and turnover is almost compensated by the biomass growth and recruitment. Under TFE, self-thinning only existed in the years before 2004 according to the model, because a drop of tree density was induced by preceding drought mortality in 2003, which suppressed the competition between trees in the model afterwards. The gain of biomass (labeled as 'growth' in green in Figure 11) also decreased under TFE in comparison with CTL. Moreover, when we grouped the mortality rate simulated for 20 cohorts into three classes according to their DBH $(<20 \mathrm{~cm}, 20-40 \mathrm{~cm}$ and $>40 \mathrm{~cm})$ we can further evaluate the model performance (Figure 12). Under CTL, the model produced higher mortality rate (2.0\%) than the observation (2001:2008 mean: 1.1\%-1.3\%) in three classes. In other words, the modeled self-thinning rate was probably higher than that in reality since the mortality rate observed was only $0.4 \%$ in year 2001 . Under TFE, the model performed differently for each size class. For the small-sized class with $\mathrm{DBH}<20 \mathrm{~cm}$, the model underestimated the mortality rate compared to observations after 2006. For the medium-sized class (DBH: 20-40cm), the modeled mortality rate was comparable with observation until 2004. For the large-sized class group, the model can estimate successfully the large mortality observed in-situ from 2004-2005. Overall, the averaged mortality rate was comparable between observation and model simulation. The model-observation gap in year $2005,2.7 \%$ in model simulation vs. $4.8 \%$ in observation, may be due to modeled underestimation in group of $\mathrm{DBH}<20 \mathrm{~cm}$ and larger modeled individual density of this group than the reality (Figure 12 ).

Finally, we tested the performance of our hydraulic failure - mortality sub-model at another Throughfall Exclusion Experiment in the Amazon, from the Tapajos site (Nepstad et al., 2007). At this site, TFE only happened in the wet season between 2000 and 2003, with an exclusion of almost 50\% rainfall. Figure S13 shows that our model can capture the observed phenomenon of a higher mortality rate found at Tapajos especially in trees with diameter $>30 \mathrm{~cm}$ although the modeled mortality rate is lower than that in the field measurement. Our model also simulates the net biomass increase at Tapajos under CTL and the great biomass loss under TFE. The two parameters of our hydraulic failure - mortality model (drought exposure threshold and mortality fraction each day upon exceeding the threshold), which are not directly observable, were effectively calibrated at Caxiuana but the model is also successfully evaluated at Tapajos site. Given the complexity of drought-mortality relationships which lack a unified theory, this shows high performances for the new parameterization we proposed in the study.

\section{Discussion}

\subsection{Model improvements by new parameterizations of hydraulic transport}

The original ORCHIDEE-CAN model included a limit from transpiration supply based on water transport and resistances along a water potential gradient (Naudts et al., 2015). Nonetheless, the constant value assumed for $\Psi_{\text {leaf }}$, the lack of a dynamic 
https://doi.org/10.5194/gmd-2021-362

Preprint. Discussion started: 20 December 2021

(c) Author(s) 2021. CC BY 4.0 License.

(c) (i)

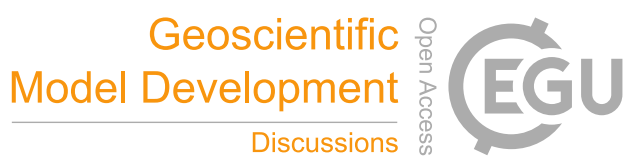

simulation of $\Psi_{\text {stem }}$ and $\Psi_{\text {root }}$ and conductivities limit the mechanistic basis of the approach. To make a step forward, the new hydraulic module presented here tracks the water flow continuum from the soil to the atmosphere. The water potentials $\Psi_{\text {leaf }}$, $\Psi_{\text {stem }}, \Psi_{\text {root }}$ are updated at each half-hour time step, based upon a Supply-Demand framework of minimization of difference between water demand and water supply at organ-level. Besides improvements in modeling the processes of vertical water transport, our hydraulic module also considers the tissue water storage and the dynamics of water flow between different organs, both of which are bounded by the capacitance and water volume. The water storage capacity, can affect the water potential and determine the tolerable duration of desiccation before severe water potentials are reached (Gleason et al., 2014). For example, in the model, stem sapwood water storage can be discharged under CTL during both wet and dry periods, and this contribution can be larger than that from vertical water flow. In contrast, under TFE, the stem sapwood water pool is not always refilled overnight in the dry season (Figure S14). Martinez-Vilalta et al. (2019) also found that a more explicit consideration of water pools helps advance the monitoring and prediction of mortality risk, although more experimental evidence is required for verifying the relationship between relative water content and mortality probability.

Besides the capacity of each organ, stem hydraulic safety indicators like water potential at which $50 \%$ of stem conductance 515 lost $\left(\Psi_{50}\right)$ can be modeled directly, and used as an indicator of tree responses to drought events. This variable influences the maximum drought exposure threshold proposed in our model, which varies among specific tree species, tree size and different growth conditions (Blackman et al., 2016). In a previous study at this site, Rowland et al. (2015) found vulnerable and resistant genera have contrasting vulnerability to hydraulic deterioration. Vulnerable trees with larger DBH displayed higher conductivity loss under experimental drought and less negative $\Psi_{50}$. However, in a more recent study with much more field data in Bittencourt et al. (2020), the variability of hydraulic traits among species is also evident and the importance of particular hyper-dominant species becomes notable too in affecting the overall species and size patterns. Naudts et al (2015) related stem conductivity to $\Psi_{\text {soil-root }}$ with $\Psi_{50}$ and another shape parameter as an adjustment. In our model, we built sigmoidal relationships between conductance and $\Psi_{\text {stem }}$, of which the slope parameter assesses the sensitivity of conductance loss to decline in water potential that can correspond to different plants water regulation strategies. Through involving trait-related parameters, our model could be used to reflect isohydric or anisohydric patterns although these two parameters are challenging to calibrate for highly diverse tropical forests (e.g Maréchaux et al. (2015)).

Recently, there is expansion in the availability of the hydraulic parameters for tropics, but mainly for xylem and leaves. Although the sensitivity analysis of Supply-Demand theory in Sperry et al. (2016) suggested that the usage of single stem vulnerability curve would not bring more error to transpiration than the true segmented mode (that is, separate leaf, stem and root curves) as long as the leaf/stem $\Psi_{50}$ and root/stem $\Psi_{50}$ closer to 1 , our study included vulnerability segmentation of leaf, stem and root to facilitate the coherent representation of the soil-root-stem-leaf continuum. Besides, the possible contextdependent trait coordination also needs to be noticed in parameterizing models (Maréchaux et al., 2020), e.g. the relationship between leaf turgor loss point and leaf area, which will benefit the diversity in vegetation models. 
With water transport from vertical gradient of potentials and changes in water storage, ORCHIDEE-CAN-NHA produced dynamic and reasonable water potentials (Figure S8) and conductance at leaf, stem and root levels. Based on the improved hydraulic architecture, we implemented an empirical algorithm that assumes a fixed fraction of trees will die after 15 days of continuous sustained drought exposure with PLC $>50 \%$. Combinations of these two parameters of drought exposure threshold and mortality fraction each time could also be adapted to diverse plants traits to match mortality rates across different sites, coping with adverse conditions, e.g. tree size, different isohydric and anisohydric behaviors of stomatal regulation upon varying water status (McDowell et al., 2008). Therefore, these two parameters would need to be calibrated upon data suited to different conditions. For example, Esquivel-Muelbert et al. (2017) found that wet-affiliated genera tends to show higher drought-induced mortality than dry-affiliated ones. Assigning higher mortality fraction for wet-affiliated genera upon such condition can be a solution to test different levels of mortality fraction parameters.

The Supply-Demand framework in our model also draws on Sperry et al. (2016) that empirical expression of each continuum component, e.g. stomatal conductance, hydraulic conductivities from vulnerability curve is applied. There are also similarities between our hydraulic structure and Xu et al. (2016), in aspects that both vertical water flow and water storage capacity in leaf and stem are accounted in modelling process of water supply and demand. The major differences from Xu et al. (2016) are that our model uses transpiration supply as the leaf-level demand instead and also refines the water transport from soil-root-stem thus water potential of each organ in continuum is solved.

\subsection{Possible factors affecting tree mortality}

Our model simulations showed that larger trees suffer more severe water stress with higher PLC (Figure 9) and that the mortality fraction is consequently the highest in groups with $\mathrm{DBH}>40 \mathrm{~cm}$. This uses the theory that longer vertical water transport pathway in taller trees can intensify the height-dependent hydraulic limitation (Grote et al., 2016) and site-level experimental evidence (Rowland et al., 2015). Such size-regulated mortality has also been corroborated by Bennett et al. (2015). Hendrik and Maxime (2017) summarized that drought can be more detrimental on growth and mortality rates of larger trees. Klos et al. (2009) also found that older and denser stands are more susceptible to drought damage, but that the mortalityheight relationship can also be relaxed by species diversity, for example, the taxonomic identity also controls the traits-size relationship (Bittencourt et al., 2020). Environmental gradients of climate conditions and concurrent competition can also affect the height-mortality risk relationship (Stovall et al., 2019), and co-explain the forest mortality patterns (Young et al., 2017). Conversely, the benefits of deeper root systems potentially may allow tall trees to avoid drought stress (Trugman et al.,

565 2021). Simulated water content in bottom soil layers did not counteract the embolism under dry season in our study, so we captured the positive height-mortality relationship observed at this site. Nevertheless, in the Caxiuanã field measurements of Rowland et al (2015), trees of similar size also showed different vulnerability ( $\left.\Psi_{50}\right)$, which suggests the influence of other 
https://doi.org/10.5194/gmd-2021-362

Preprint. Discussion started: 20 December 2021

(c) Author(s) 2021. CC BY 4.0 License.

(c) (i)

anatomical traits, for instance, wood density, which is already prescribed as PFT-based parameter in simulation setup. Such kind of within PFT variation cannot yet be accounted for in model. Wood density with intra-individual variability is intimately linked with tree mortality, and has been found to explain variation in tropical mortality rate across sites through a hierarchical Bayesian approach (Kraft et al., 2010). Plant functional traits like xylem, leaf specific conductivities and capacitances are inversely related to the wood density (Meinzer et al., 2008). On the one hand, taller trees with lower wood density (Rozendaal et al., 2020), would be expected to present higher sapwood conductivity although the overall effect would depend on the forest type, and growth conditions (Fajardo, 2018;Meinzer et al., 2008). On the other hand, height-dependent water limitation weakens the stem hydraulic conductivity. Such tradeoffs co-determine the resistance to hydraulic failure.

Under extreme drought, hydraulic traits are also highly important factors for mortality risk. Trees with high cavitation resistance and wide hydraulic safety margin can endure longer desiccation (Blackman et al., 2019). Although xylem anatomical traits directly related to conductivity better reflect the whole-tree performance (Fan et al., 2012), the relative importance of climate conditions, plant functional and hydraulic traits in determining forest mortality risk encountering drought needs further validation with large amount of experimental observations (Aleixo et al., 2019).

\subsection{Model limitations and directions for future development}

Several potentially important ecological processes related to plant hydraulics and mortality warrant further consideration.

585 First, tree mortality risk, in the simulations, is mainly triggered by drought-induced water stress, but soil water limitation can also be alleviated by enhanced tree survival through increasing nutrients uptake, to increase water use efficiency and reduce negative effects of droughts (Wang et al., 2012). Fast growth rate, however, is associated with higher mortality probability (see Rozendaal et al. (2020) for spatial relationship between basal area growth, diameter and possibility of mortality in Amazonia tropical forest). Discounting the demographic association between tree growth and mortality rate could lead to underestimation

590 of mortality in model simulations. Representations of these interactions should be further incorporated to increase model credibility under various environments. Secondly, the plant functional type classification used in ORCHIDEE-CAN-NHA does not capture hydraulic variation. Some researchers proposed hydraulic trait-based classifications (Anderegg, 2015) or hydraulic functional types (Liu et al., 2021b), which may better represent isohydric and anisohydric behaviors affecting water potential and stomatal regulation. Accounting for the variability in hydraulic traits would be important to properly model in future 595 ecosystem-atmosphere feedback effects (Anderegg et al., 2018; Powell et al., 2018). More specifically, some traits are also but not always found to vary with tree size, like $\Psi_{50}$, conductivity and the number of days of exposure to severe drought that a tree can tolerate. Our assumption of fixed $\Psi_{50}$ values for all 20 cohorts may lead to miscalculation of mortality rates in different classes, e.g. overestimation for PLC in smaller cohorts and underestimation for PLC in larger cohorts. Therefore, future research should focus on discerning the empirical connection between species-specific hydraulic strategies toward mortality by distinguishing vegetation functional groups. Thirdly, legacy or memory effects are not fully accounted here. The impacts 
of drought on increasing tree mortality can last for at least two years after an extreme climatic event (Aleixo et al., 2019). Some cumulated or memory indicators may help tackle such problems. For example, we can consider the effects of past drought events on current tree growth by multiplying the drought intensity with the inverse of time passed (Franklin et al., 1987). Finally, different threshold indicators like relative water content and turgor loss point can also be tested in mortality triggering process (Sapes et al., 2019;Zhu et al., 2018).

Besides future developments of the hydraulic module, more calibration and understanding of the lethal threshold required for hydraulic failure is clearly necessary. We call for that more observed hydraulic traits data for tropical trees, including detailed vulnerability, to support more reasonable and appropriate parameterization scheme in mortality risk modeling. For example, the point of no return from drought-induced xylem embolism in aspects of water potential (turgor loss point), conductivity and relative water content. Remote sensing products of vegetation optical depth (VOD), proportional to the vegetation water content, may help benchmark the capacitance dynamics. In addition, in this study we have only calibrated the new hydraulic architecture against observations from one experimentally droughted site. Expanding this method to other drought experiment sites to generalize the model performance is required. For example, this future work could address to what

615 extent the 2005 and 2010 drought affected forest dynamics in western Amazonia. Large-scale mortality observations and more comprehensive mortality benchmarking datasets are also required to evaluate the hydraulic architecture in process-based model (Adams et al., 2013;Allen et al., 2010).

\section{Conclusion}

Our study proposes a new mechanistic hydraulic architecture module, ORCHIDEE-CAN-NHA, which simulates dynamic xylem cavitation indicator of percentage loss of conductance (PLC) through modeling the water flow in soil-root-stem-leaf continuum and water charge from storage. The model was calibrated against observations from the Caxiuanã throughfall exclusion field experiment in the eastern Amazon, during 2001 to 2008, with regard to the seasonal variability in transpiration, soil moisture and productivity. Besides the improvement of hydraulic architecture, we also built a relationship between PLC and tree mortality rate via two empirical parameters, drought exposure duration, which determines the mortality frequency and the mortality fraction in each day once exceeding the exposure. Our model produces comparable annual tree mortality rates with observations over the study period. Introduction of mechanistic hydraulic architecture in land surface models can help provide a window through which we can enable prediction for mortality under future possible drought events. We also call for more available hydraulic traits and vulnerability data for testing the generalization of model performance.

\section{Appendix}


https://doi.org/10.5194/gmd-2021-362

Preprint. Discussion started: 20 December 2021

(c) Author(s) 2021. CC BY 4.0 License.

(c) (1)

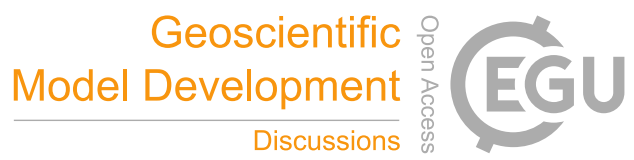

Table A1 Parameters used in new hydraulic architecture model. These parameters are selected from the range recorded by literature that we have analyzed.

\begin{tabular}{|c|c|c|c|c|}
\hline Symbol & Description & Unit & Value & Source \\
\hline$c_{\text {leaf }}$ & Leaf capacitance & $\mathrm{mmol} \mathrm{m}{ }^{-2} \mathrm{MPa}^{-1}$ & 670 & De Kauwe et al. (2020) \\
\hline$c_{\text {stem }}$ & Stem capacitance & $\mathrm{kg} \mathrm{m}^{-3} \mathrm{MPa}^{-1}$ & 130 & Xu et al. (2016) \\
\hline$c_{\text {root }}$ & Root capacitance & $\mathrm{kg} \mathrm{m}^{-3} \mathrm{MPa}^{-1}$ & 150 & Modified from $C_{\text {stem }}$ \\
\hline$S L A$ & Specific leaf area & $\mathrm{m}^{2} \mathrm{~kg}^{-1}$ & 16.6 & Kattge et al. (2011) \\
\hline$L D M C$ & Leaf dry matter content & $\mathrm{g} \mathrm{g}^{-1}$ & 0.2 & Kattge et al. (2011) \\
\hline$W C$ & $\begin{array}{l}\text { mass of water per unit of } \\
\text { sapwood volume }\end{array}$ & $\mathrm{mol} \mathrm{m}^{-3}$ & 25000 & Suzuki (1999) \\
\hline$W D$ & Wood density & $\mathrm{g} \mathrm{cm}^{-3}$ & 0.645 & Chave et al. (2006) \\
\hline ratio $_{\text {root:shoot }}$ & Root shoot ratio & $\mathrm{g} \mathrm{g}^{-1}$ & 0.25 & Mokany et al. (2006) \\
\hline $\operatorname{root}_{w c}$ & root water content & $\mathrm{mmol} \mathrm{g}^{-1}$ & 35 & $\begin{array}{c}\text { Markesteijn and Poorter } \\
\text { (2009) }\end{array}$ \\
\hline$\rho_{\text {root }}$ & Root density & $\mathrm{g} \mathrm{cm}^{-3}$ & 0.503 & Schuldt et al. (2013) \\
\hline$k_{\text {leaf, } \max }$ & $\begin{array}{l}\text { Maximum leaf hydraulic } \\
\text { conductance per unit leaf } \\
\text { area }\end{array}$ & $\mathrm{mmol} \mathrm{m}{ }^{-2} \mathrm{~s}^{-1} \mathrm{MPa}^{-1}$ & 15 & Sack (2006) \\
\hline$k_{\text {stem, } \max }$ & $\begin{array}{c}\text { Maximum sapwood } \\
\text { hydraulic conductance per } \\
\text { unit leaf area }\end{array}$ & $\mathrm{mmol} \mathrm{m} \mathrm{m}^{-2} \mathrm{~s}^{-1} \mathrm{MPa}^{-1}$ & $15^{*}$ & Hickler et al. (2006) \\
\hline
\end{tabular}


Maximum root hydraulic

$k_{\text {root, } \max \quad \text { conductance per unit leaf }}$ area

$\mathrm{mmol} \mathrm{m} \mathrm{m}^{-2} \mathrm{~s}^{-1} \mathrm{MPa}^{-1}$

10

Modified from $k_{\text {stem, } \max }$

$a_{\text {leaf }}$

Shape parameter for $k_{\text {leaf }}$ Vs.

$$
\Psi_{\text {leaf }} \text { curve }
$$

Shape parameter for $k_{\text {stem }}$ Vs. $\Psi_{\text {stem }}$ curve

$a_{\text {root }}$

$\Psi_{50, \text { leaf }}$

$\Psi_{50, \text { stem }}$

$\Psi_{50, \text { root }}$

$g_{\max }$

$g_{\min }$

$\Psi_{50, g s}$

$a_{g s}$

$\frac{L \times R a d}{L \times \operatorname{Rad}+L_{k}}$
Shape parameter for $k_{\text {root }}$ Vs. $\Psi_{\text {root }}$ curve

$\Psi_{\text {leaf }}$ at $50 \%$ loss of leaf conductance

$\Psi_{\text {stem }}$ at $50 \%$ loss of stem sapwood conductance

$\Psi_{\text {root }}$ at $50 \%$ loss of root conductance

Maximum stomatal conductance in Eq. 24

Mininum stomatal conductance

$\Psi_{\text {leaf }}$ at $50 \%$ decline in stomatal conductance

Shape parameter for $g_{s}$ vs. $\Psi_{\text {leaf }}$ curve

In this term, the function of short-wave radiation, is used to ensure the $g_{s}$ at night to be
$\mathrm{MPa}$

$[-3.8,-0.5]$ in Bartlett et al (2019)

[-3, -0.75] in Bartlett et al (2019)

$[-3,-0.75]$ in Bartlett et al (2019)

$[-3,-0.75]$ in Bartlett et al (2019)

$\mathrm{mmol} \mathrm{m}{ }^{-2} \mathrm{~s}^{-1}$

700

Franks and Brodribb (2005)

$\mathrm{mmol} \mathrm{m}{ }^{-2} \mathrm{~s}^{-1}$

10

Franks and Brodribb (2005)

Bartlett et al (2016) 
https://doi.org/10.5194/gmd-2021-362

Preprint. Discussion started: 20 December 2021

(c) Author(s) 2021. CC BY 4.0 License.

(c) (i)

close to 0

$6 \overline{35}$

${ }^{*}$ In Hickler et al (2006), the maximum sapwood conductivity of $50 * 10^{-4} \mathrm{~m}^{2} \mathrm{~s}^{-1} \mathrm{MPa}^{-1}$ can be converted to $\sim 15 \mathrm{mmol} \mathrm{m}^{-2} \mathrm{~s}^{-1}$ $\mathrm{MPa}^{-1}$ if we assume sapwood area/leaf area of 0.0016 (value falls in (Gotsch et al., 2010), and tree height of 30m.

Table A2 Outputs variables calculated by ORCHIDEE-CAN-NHA.

\begin{tabular}{|c|c|c|c|}
\hline Category & Symbol & Description & Unit \\
\hline \multirow{4}{*}{ Water potentials } & $\psi_{\text {soil-root }}$ & soil water potential in root zone & $\mathrm{MPa}$ \\
\hline & $\psi_{\text {root }}$ & Root water potential & $\mathrm{MPa}$ \\
\hline & $\psi_{\text {stem }}$ & Stem water potential & $\mathrm{MPa}$ \\
\hline & $\psi_{\text {leaf }}$ & Leaf water potential & $\mathrm{MPa}$ \\
\hline \multirow{3}{*}{$\begin{array}{l}\text { Hydraulic } \\
\text { conductances }\end{array}$} & $k_{\text {root }}$ & Root hydraulic conductance & $\mathrm{mmol} \mathrm{m} \mathrm{m}^{-2} \mathrm{~s}^{-1} \mathrm{MPa}^{-1}$ \\
\hline & $k_{\text {stem }}$ & Stem sapwood hydraulic conductance & $\mathrm{mmol} \mathrm{m} \mathrm{m}^{-2} \mathrm{~s}^{-1} \mathrm{MPa}^{-1}$ \\
\hline & $k_{\text {leaf }}$ & Leaf hydraulic conductance & $\mathrm{mmol} \mathrm{m} \mathrm{m}^{-2} \mathrm{~s}^{-1} \mathrm{MPa}^{-1}$ \\
\hline \multirow{3}{*}{ Water storage } & $m_{\text {root }}$ & Water volume in the root & mmol \\
\hline & $m_{\text {stem }}$ & Water volume in the stem & mmol \\
\hline & $m_{\text {leaf }}$ & Water volume in the leaf & mmol \\
\hline \multirow[t]{2}{*}{ Cavitation } & $P L C$ & Percentage loss of stem conductance & $\%$ \\
\hline & counter $_{P L C 50}$ & $\begin{array}{l}\text { Number of continuous days with } \\
\quad P L C>50 \% \text { (exposure) }\end{array}$ & days \\
\hline \multicolumn{4}{|l|}{ Mortality } \\
\hline & circ_class_mor & $\begin{array}{l}\text { Tree mortality for each circumference } \\
\text { class due to exposure to } P L C>50 \%\end{array}$ & $1 \mathrm{~m}^{-2}$ \\
\hline
\end{tabular}


https://doi.org/10.5194/gmd-2021-362

Preprint. Discussion started: 20 December 2021

(c) Author(s) 2021. CC BY 4.0 License.

(c) (1)

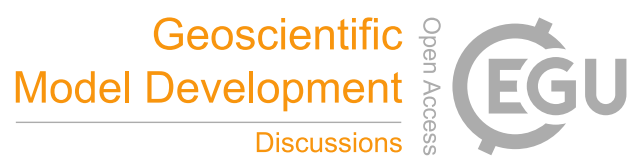

Code/Data Availability Statement

The ORCHIDEE-CAN-NHA model (r7236) code used in this study is archived at https://doi.org/10.14768/8C2D06FB-0020-

645 4BC5-A831-C876F5FBBFE9. The detailed code used to reproduce the analysis and figures is publicly available at doi: $10.5281 /$ zenodo. 5721245 .

Author contributions

YY, EJ, PC, and NV designed the study. YY and EJ developed the code. YY conducted the analysis. YY wrote the manuscript.

650 All authors provided comments and contributed to the final version of the paper.

Competing interests

The authors declare that they have no competing interests.

655 Acknowledgements

This work was financially supported by the CLAND Convergence Institute funded by ANR (16-CONV-0003). YY also acknowledges support from Make Our Planet Great Again (MOPGA) Scholarship. 


\section{References}

Adams, H. D., Williams, A. P., Xu, C., Rauscher, S. A., Jiang, X., and McDowell, N. G.: Empirical and process-based approaches to climate-induced forest mortality models, Frontiers in plant science, 4, 438, 2013.

Adams, H. D., Zeppel, M. J., Anderegg, W. R., Hartmann, H., Landhäusser, S. M., Tissue, D. T., Huxman, T. E., Hudson, P. J., Franz, T. E., and Allen, C. D.: A multi-species synthesis of physiological mechanisms in drought-induced tree mortality, Nature ecology \& evolution, 1, 1285-1291, 2017.

Aleixo, I., Norris, D., Hemerik, L., Barbosa, A., Prata, E., Costa, F., and Poorter, L.: Amazonian rainforest tree mortality driven by climate and functional traits, Nature Climate Change, 9, 384-388, 2019.

Allen, C. D., Macalady, A. K., Chenchouni, H., Bachelet, D., McDowell, N., Vennetier, M., Kitzberger, T., Rigling, A., Breshears, D. D., and Hogg, E. T.: A global overview of drought and heat-induced tree mortality reveals emerging climate change risks for forests, Forest ecology and management, 259, 660-684, 2010.

Allen, C. D., Breshears, D. D., and McDowell, N. G.: On underestimation of global vulnerability to tree mortality and forest die-off from hotter drought in the Anthropocene, Ecosphere, 6, 1-55, 2015.

Anderegg, W. R.: Spatial and temporal variation in plant hydraulic traits and their relevance for climate change impacts on vegetation, New Phytologist, 205, 1008-1014, 2015.

675 Anderegg, W. R., Flint, A., Huang, C.-y., Flint, L., Berry, J. A., Davis, F. W., Sperry, J. S., and Field, C. B.: Tree mortality predicted from drought-induced vascular damage, Nature Geoscience, 8, 367-371, 2015.

Anderegg, W. R., Konings, A. G., Trugman, A. T., Yu, K., Bowling, D. R., Gabbitas, R., Karp, D. S., Pacala, S., Sperry, J. S., and Sulman, B. N.: Hydraulic diversity of forests regulates ecosystem resilience during drought, Nature, 561, 538-541, 2018.

Bartlett, M. K., Klein, T., Jansen, S., Choat, B., and Sack, L.: The correlations and sequence of plant stomatal, hydraulic, and wilting responses to drought, Proceedings of the National Academy of Sciences, 113, 13098-13103, 2016.

Bartlett, M. K., Detto, M., and Pacala, S. W.: Predicting shifts in the functional composition of tropical forests under increased drought and CO 2 from trade-offs among plant hydraulic traits, Ecology letters, 22, 67-77, 2019.

Bittencourt, P. R., Oliveira, R. S., da Costa, A. C., Giles, A. L., Coughlin, I., Costa, P. B., Bartholomew, D. C., Ferreira, L. V., Vasconcelos, S. S., and Barros, F. V.: Amazonia trees have limited capacity to acclimate plant hydraulic properties in response to long-term drought, Global change biology, 26, 3569-3584, 2020.

Blackman, C. J., Pfautsch, S., Choat, B., Delzon, S., Gleason, S. M., and Duursma, R. A.: Toward an index of desiccation time to tree mortality under drought, Plant, cell \& environment, 39, 2342-2345, 2016.

Blackman, C. J., Li, X., Choat, B., Rymer, P. D., De Kauwe, M. G., Duursma, R. A., Tissue, D. T., and Medlyn, B. E.: Desiccation time during drought is highly predictable across species of Eucalyptus from contrasting climates, New Phytologist, 
https://doi.org/10.5194/gmd-2021-362

Preprint. Discussion started: 20 December 2021

(c) Author(s) 2021. CC BY 4.0 License.

(c) (i)

Bonan, G., Williams, M., Fisher, R., and Oleson, K.: Modeling stomatal conductance in the earth system: linking leaf wateruse efficiency and water transport along the soil-plant-atmosphere continuum, Geoscientific Model Development, 7, 21932222, 2014.

Brienen, R. J., Phillips, O. L., Feldpausch, T. R., Gloor, E., Baker, T. R., Lloyd, J., Lopez-Gonzalez, G., Monteagudo-Mendoza,

A., Malhi, Y., and Lewis, S. L.: Long-term decline of the Amazon carbon sink, Nature, 519, 344-348, 2015.

Brodribb, T. J., and Cochard, H.: Hydraulic failure defines the recovery and point of death in water-stressed conifers, Plant physiology, 149, 575-584, 2009.

Brodribb, T. J., Powers, J., Cochard, H., and Choat, B.: Hanging by a thread? Forests and drought, Science, 368, 261-266, 2020.

700 Carswell, F., Costa, A., Palheta, M., Malhi, Y., Meir, P., de Pr Costa, J., Ruivo, M. d. L., do Sm Leal, L., Costa, J., and Clement, R.: Seasonality in $\mathrm{CO} 2$ and $\mathrm{H} 2 \mathrm{O}$ flux at an eastern Amazonian rain forest, Journal of Geophysical Research: Atmospheres, 107, LBA 43-41-LBA 43-16, 2002.

Chave, J., Muller-Landau, H. C., Baker, T. R., Easdale, T. A., Steege, H. t., and Webb, C. O.: Regional and phylogenetic variation of wood density across 2456 neotropical tree species, Ecological applications, 16, 2356-2367, 2006.

705 Choat, B.: Predicting thresholds of drought-induced mortality in woody plant species, Tree physiology, 33, 669-671, 2013.

Choat, B., Brodribb, T. J., Brodersen, C. R., Duursma, R. A., López, R., and Medlyn, B. E.: Triggers of tree mortality under drought, Nature, 558, 531-539, 2018.

Cochard, H., and Delzon, S.: Hydraulic failure and repair are not routine in trees, Annals of Forest Science, 70, 659-661, 2013. da Costa, A. C. L., Galbraith, D., Almeida, S., Portela, B. T. T., da Costa, M., Junior, J. d. A. S., Braga, A. P., de Gonçalves, P. 710 H., de Oliveira, A. A., and Fisher, R.: Effect of $7 \mathrm{yr}$ of experimental drought on vegetation dynamics and biomass storage of an eastern Amazonian rainforest, New Phytologist, 187, 579-591, 2010.

De Kauwe, M. G., Medlyn, B. E., Ukkola, A. M., Mu, M., Sabot, M. E., Pitman, A. J., Meir, P., Cernusak, L., Rifai, S. W., and Choat, B.: Identifying areas at risk of drought-induced tree mortality across South-Eastern Australia, Global Change Biology, 2020 .

715 Delbart, N., Ciais, P., Chave, J., Viovy, N., Malhi, Y., and Le Toan, T.: Mortality as a key driver of the spatial distribution of aboveground biomass in Amazonian forest: results from a dynamic vegetation model, 2010.

Dewar, R., Mauranen, A., Mäkelä, A., Hölttä, T., Medlyn, B., and Vesala, T.: New insights into the covariation of stomatal, mesophyll and hydraulic conductances from optimization models incorporating nonstomatal limitations to photosynthesis, New Phytologist, 217, 571-585, 2018.

720 Duffy, P. B., Brando, P., Asner, G. P., and Field, C. B.: Projections of future meteorological drought and wet periods in the Amazon, Proceedings of the National Academy of Sciences, 112, 13172-13177, 2015.

Eller, C. B., Rowland, L., Oliveira, R. S., Bittencourt, P. R., Barros, F. V., da Costa, A. C., Meir, P., Friend, A. D., Mencuccini, M., and Sitch, S.: Modelling tropical forest responses to drought and El Niño with a stomatal optimization model based on xylem hydraulics, Philosophical Transactions of the Royal Society B: Biological Sciences, 373, 20170315, 2018. 
https://doi.org/10.5194/gmd-2021-362

Preprint. Discussion started: 20 December 2021

(c) Author(s) 2021. CC BY 4.0 License.

(c) (i)

Eller, C. B., Rowland, L., Mencuccini, M., Rosas, T., Williams, K., Harper, A., Medlyn, B. E., Wagner, Y., Klein, T., and Teodoro, G. S.: Stomatal optimization based on xylem hydraulics (SOX) improves land surface model simulation of vegetation responses to climate, New Phytologist, 226, 1622-1637, 2020.

Esquivel-Muelbert, A., Galbraith, D., Dexter, K. G., Baker, T. R., Lewis, S. L., Meir, P., Rowland, L., da Costa, A. C. L., Nepstad, D., and Phillips, O. L.: Biogeographic distributions of neotropical trees reflect their directly measured drought tolerances, Scientific reports, 7, 1-11, 2017.

Fajardo, A.: Insights into intraspecific wood density variation and its relationship to growth, height and elevation in a treeline species, Plant Biology, 20, 456-464, 2018.

Fan, Z. X., Zhang, S. B., Hao, G. Y., Ferry Slik, J., and Cao, K. F.: Hydraulic conductivity traits predict growth rates and adult stature of 40 Asian tropical tree species better than wood density, Journal of Ecology, 100, 732-741, 2012.

735 Fisher, R., Williams, M., Da Costa, A. L., Malhi, Y., Da Costa, R., Almeida, S., and Meir, P.: The response of an Eastern Amazonian rain forest to drought stress: results and modelling analyses from a throughfall exclusion experiment, Global Change Biology, 13, 2361-2378, 2007.

Fisher, R. A., Williams, M., Do Vale, R. L., Da Costa, A. L., and Meir, P.: Evidence from Amazonian forests is consistent with isohydric control of leaf water potential, Plant, Cell \& Environment, 29, 151-165, 2006.

740 Franklin, J. F., Shugart, H. H., and Harmon, M. E.: Tree death as an ecological process, BioScience, 37, 550-556, 1987.

Franks, P., and Brodribb, T. J.: Stomatal control and water transport in the xylem, in: Vascular transport in plants, Elsevier, 6989, 2005.

Gleason, S. M., Blackman, C. J., Cook, A. M., Laws, C. A., and Westoby, M.: Whole-plant capacitance, embolism resistance and slow transpiration rates all contribute to longer desiccation times in woody angiosperms from arid and wet habitats, Tree 745 Physiology, 34, 275-284, 2014.

Gotsch, S. G., Geiger, E. L., Franco, A. C., Goldstein, G., Meinzer, F. C., and Hoffmann, W. A.: Allocation to leaf area and sapwood area affects water relations of co-occurring savanna and forest trees, Oecologia, 163, 291-301, 2010.

Grote, R., Gessler, A., Hommel, R., Poschenrieder, W., and Priesack, E.: Importance of tree height and social position for drought-related stress on tree growth and mortality, Trees, 30, 1467-1482, 2016.

750 Gustafson, E. J., and Sturtevant, B. R.: Modeling forest mortality caused by drought stress: implications for climate change, Ecosystems, 16, 60-74, 2013.

Hammond, W. M., Yu, K., Wilson, L. A., Will, R. E., Anderegg, W. R., and Adams, H. D.: Dead or dying? Quantifying the point of no return from hydraulic failure in drought-induced tree mortality, New Phytologist, 223, 1834-1843, 2019.

Hartmann, H.: Carbon starvation during drought-induced tree mortality-are we chasing a myth?, 2015.

755 Hendrik, D., and Maxime, C.: Assessing drought-driven mortality trees with physiological process-based models, Agricultural and Forest Meteorology, 232, 279-290, 2017.

Hickler, T., Prentice, I. C., Smith, B., Sykes, M. T., and Zaehle, S.: Implementing plant hydraulic architecture within the LPJ Dynamic Global Vegetation Model, Global Ecology and Biogeography, 15, 567-577, 2006. 
https://doi.org/10.5194/gmd-2021-362

Preprint. Discussion started: 20 December 2021

(c) Author(s) 2021. CC BY 4.0 License.

(c) (i)

Joetzjer, E., Maignan, F., Chave, J., Goll, D., Poulter, B., Barichivich, J., Maréchaux, I., Luyssaert, S., Guimberteau, M. and

Naudts, K. The importance of tree demography and root water uptake for modelling the carbon and water cycles of Amazonia. under review, 2021.

Kattge, J., Diaz, S., Lavorel, S., Prentice, I. C., Leadley, P., Bönisch, G., Garnier, E., Westoby, M., Reich, P. B., and Wright, I. J.: TRY-a global database of plant traits, Global change biology, 17, 2905-2935, 2011.

Kennedy, D., Swenson, S., Oleson, K. W., Lawrence, D. M., Fisher, R., Lola da Costa, A. C., and Gentine, P.: Implementing

plant hydraulics in the community land model, version 5, Journal of Advances in Modeling Earth Systems, 11, 485-513, 2019.

Klos, R. J., Wang, G. G., Bauerle, W. L., and Rieck, J. R.: Drought impact on forest growth and mortality in the southeast USA: an analysis using Forest Health and Monitoring data, Ecological Applications, 19, 699-708, 2009.

Kraft, N. J., Metz, M. R., Condit, R. S., and Chave, J.: The relationship between wood density and mortality in a global tropical forest data set, New Phytologist, 188, 1124-1136, 2010.

770 Lewis, S. L., Brando, P. M., Phillips, O. L., van der Heijden, G. M., and Nepstad, D.: The 2010 amazon drought, Science, 331, 554-554, 2011.

Lin, Y. S., Medlyn, B. E., Duursma, R. A., Prentice, I. C., Wang, H., Baig, S., Eamus, D., De Dios, V. R., Mitchell, P., and Ellsworth, D. S.: Optimal stomatal behaviour around the world, Nature Climate Change, 5, 459-464, 2015.

Liu, Q., Peng, C., Schneider, R., Cyr, D., Liu, Z., Zhou, X., and Kneeshaw, D.: TRIPLEX-Mortality model for simulating drought-induced tree mortality in boreal forests: Model development and evaluation, Ecological Modelling, 455, 109652, 2021a.

Liu, Y., Holtzman, N. M., and Konings, A. G.: Global ecosystem-scale plant hydraulic traits retrieved using model-data fusion, Hydrology and Earth System Sciences, 25, 2399-2417, 2021 b.

Maréchaux, I., Bartlett, M. K., Sack, L., Baraloto, C., Engel, J., Joetzjer, E., and Chave, J.: Drought tolerance as predicted by

leaf water potential at turgor loss point varies strongly across species within an Amazonian forest, Functional Ecology, 29, 1268-1277, 2015.

Maréchaux, I., Saint-André, L., Bartlett, M. K., Sack, L., and Chave, J.: Leaf drought tolerance cannot be inferred from classic leaf traits in a tropical rainforest, Journal of Ecology, 108, 1030-1045, 2020.

Maréchaux, I., Langerwisch, F., Huth, A., Bugmann, H., Morin, X., Reyer, C. P., Seidl, R., Collalti, A., Dantas de Paula, M.,

and Fischer, R.: Tackling unresolved questions in forest ecology: The past and future role of simulation models, Ecology and evolution, 11, 3746-3770, 2021.

Markesteijn, L., and Poorter, L.: Seedling root morphology and biomass allocation of 62 tropical tree species in relation to drought-and shade-tolerance, Journal of Ecology, 97, 311-325, 2009.

Martinez-Vilalta, J., Anderegg, W. R., Sapes, G., and Sala, A.: Greater focus on water pools may improve our ability to understand and anticipate drought-induced mortality in plants, New Phytologist, 223, 22-32, 2019.

McDowell, N., Pockman, W. T., Allen, C. D., Breshears, D. D., Cobb, N., Kolb, T., Plaut, J., Sperry, J., West, A., and Williams, D. G.: Mechanisms of plant survival and mortality during drought: why do some plants survive while others succumb to 
https://doi.org/10.5194/gmd-2021-362

Preprint. Discussion started: 20 December 2021

(c) Author(s) 2021. CC BY 4.0 License.

(c) (i)

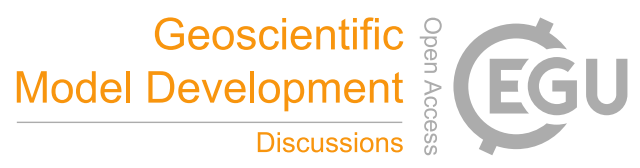

drought?, New phytologist, 178, 719-739, 2008.

McDowell, N., Allen, C. D., Anderson-Teixeira, K., Brando, P., Brienen, R., Chambers, J., Christoffersen, B., Davies, S.,

Doughty, C., and Duque, A.: Drivers and mechanisms of tree mortality in moist tropical forests, New Phytologist, 219,851 $869,2018$.

McDowell, N. G., Beerling, D. J., Breshears, D. D., Fisher, R. A., Raffa, K. F., and Stitt, M.: The interdependence of mechanisms underlying climate-driven vegetation mortality, Trends in ecology \& evolution, 26, 523-532, 2011.

Meinzer, F. C., Campanello, P. I., Domec, J.-C., Gatti, M. G., Goldstein, G., Villalobos-Vega, R., and Woodruff, D. R.:

Constraints on physiological function associated with branch architecture and wood density in tropical forest trees, Tree Physiology, 28, 1609-1617, 2008.

Meir, P., Mencuccini, M., and Dewar, R. C.: Drought-related tree mortality: addressing the gaps in understanding and prediction, New Phytologist, 207, 28-33, 2015.

Meir, P., Mencuccini, M., Binks, O., da Costa, A. L., Ferreira, L., and Rowland, L.: Short-term effects of drought on tropical

forest do not fully predict impacts of repeated or long-term drought: gas exchange versus growth, Philosophical Transactions of the Royal Society B: Biological Sciences, 373, 20170311, 2018.

Mokany, K., Raison, R. J., and Prokushkin, A. S.: Critical analysis of root: shoot ratios in terrestrial biomes, Global Change Biology, 12, 84-96, 2006.

Naudts, K., Ryder, J., McGrath, M., Otto, J., Chen, Y., Valade, A., Bellasen, V., Berhongaray, G., Bönisch, G., and Campioli,

M.: A vertically discretised canopy description for ORCHIDEE (SVN r2290) and the modifications to the energy, water and carbon fluxes, Geoscientific Model Development, 8, 2035-2065, 2015.

Nepstad, D. C., Tohver, I. M., Ray, D., Moutinho, P., and Cardinot, G.: Mortality of large trees and lianas following experimental drought in an Amazon forest, Ecology, 88, 2259-2269, 2007.

Nobre, C. A., and Borma, L. D. S.: 'Tipping points' for the Amazon forest, Current Opinion in Environmental Sustainability, $8151,28-36,2009$.

Nychka D, F. R., Paige J, Sain S, Gerber F., Iverson M.: Fields: Tools for Spatial Data

University Corporation for Atmospheric Research, Boulder, CO, USA 10.5065/D6W957CT

URL: https://github.com/NCAR/Fields. R package version 10.3, 2020.

Papastefanou, P., Zang, C. S., Pugh, T. A., Liu, D., Grams, T. E., Hickler, T., and Rammig, A.: A dynamic model for strategies

and dynamics of plant water-potential regulation under drought conditions, Frontiers in Plant Science, 11, 373, 2020.

Phillips, O. L., Aragão, L. E., Lewis, S. L., Fisher, J. B., Lloyd, J., López-González, G., Malhi, Y., Monteagudo, A., Peacock, J., and Quesada, C. A.: Drought sensitivity of the Amazon rainforest, Science, 323, 1344-1347, 2009.

Powell, T. L., Galbraith, D. R., Christoffersen, B. O., Harper, A., Imbuzeiro, H. M., Rowland, L., Almeida, S., Brando, P. M., da Costa, A. C. L., and Costa, M. H.: Confronting model predictions of carbon fluxes with measurements of Amazon forests subjected to experimental drought, New Phytologist, 200, 350-365, 2013.

Powell, T. L., Koven, C. D., Johnson, D. J., Faybishenko, B., Fisher, R. A., Knox, R. G., McDowell, N. G., Condit, R., Hubbell, 
https://doi.org/10.5194/gmd-2021-362

Preprint. Discussion started: 20 December 2021

(c) Author(s) 2021. CC BY 4.0 License.

(c) (i)

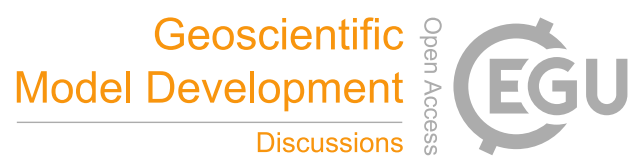

S. P., and Wright, S. J.: Variation in hydroclimate sustains tropical forest biomass and promotes functional diversity, New Phytologist, 219, 932-946, 2018.

R Development Core Team. R: A language and environment for statistical computing. Vienna, Austria: R Foundation for

Statistical Computing, available at http://www.R-project.org/ 2019.

Rao, K., Anderegg, W. R., Sala, A., Martínez-Vilalta, J., and Konings, A. G.: Satellite-based vegetation optical depth as an indicator of drought-driven tree mortality, Remote sensing of environment, 227, 125-136, 2019.

Rowland, L., da Costa, A. C. L., Galbraith, D. R., Oliveira, R., Binks, O. J., Oliveira, A., Pullen, A., Doughty, C., Metcalfe, D., and Vasconcelos, S.: Death from drought in tropical forests is triggered by hydraulics not carbon starvation, Nature, 528, 119-

Rozendaal, D. M., Phillips, O. L., Lewis, S. L., Affum-Baffoe, K., Alvarez-Davila, E., Andrade, A., Aragão, L. E., AraujoMurakami, A., Baker, T. R., and Bánki, O.: Competition influences tree growth, but not mortality, across environmental gradients in Amazonia and tropical Africa, Ecology, 101, e03052, 2020.

Sabot, M. E., De Kauwe, M. G., Pitman, A. J., Medlyn, B. E., Verhoef, A., Ukkola, A. M., and Abramowitz, G.: Plant profit maximization improves predictions of European forest responses to drought, New Phytologist, 226, 1638-1655, 2020.

Sack, L., and Holbrook, N. M.: Leaf hydraulics, Annu. Rev. Plant Biol., 57, 361-381, 2006.

Sapes, G., Roskilly, B., Dobrowski, S., Maneta, M., Anderegg, W. R., Martinez-Vilalta, J., and Sala, A.: Plant water content integrates hydraulics and carbon depletion to predict drought-induced seedling mortality, Tree physiology, 39, 1300-1312, 2019.

845 Schuldt, B., Leuschner, C., Brock, N., and Horna, V.: Changes in wood density, wood anatomy and hydraulic properties of the xylem along the root-to-shoot flow path in tropical rainforest trees, Tree physiology, 33, 161-174, 2013.

Signori-Müller, C., Oliveira, R. S., de Vasconcellos Barros, F., Tavares, J. V., Gilpin, M., Diniz, F. C., Zevallos, M. J. M., Yupayccana, C. A. S., Acosta, M., and Bacca, J.: Non-structural carbohydrates mediate seasonal water stress across Amazon forests, Nature communications, 12, 1-9, 2021.

850 Sperry, J. S., Wang, Y., Wolfe, B. T., Mackay, D. S., Anderegg, W. R., McDowell, N. G., and Pockman, W. T.: Pragmatic hydraulic theory predicts stomatal responses to climatic water deficits, New Phytologist, 212, 577-589, 2016.

Sperry, J. S., Venturas, M. D., Anderegg, W. R., Mencuccini, M., Mackay, D. S., Wang, Y., and Love, D. M.: Predicting stomatal responses to the environment from the optimization of photosynthetic gain and hydraulic cost, Plant, cell \& environment, 40 , 816-830, 2017.

855 Stovall, A. E., Shugart, H., and Yang, X.: Tree height explains mortality risk during an intense drought, Nature communications, 10, 1-6, 2019.

Suzuki, E.: Diversity in specific gravity and water content of wood among Bornean tropical rainforest trees, Ecological Research, 14, 211-224, 1999.

Trugman, A. T., Anderegg, L. D., Anderegg, W. R., Das, A. J., and Stephenson, N. L.: Why is tree drought mortality so hard to predict?, Trends in Ecology \& Evolution, 2021. 
Urli, M., Porté, A. J., Cochard, H., Guengant, Y., Burlett, R., and Delzon, S.: Xylem embolism threshold for catastrophic hydraulic failure in angiosperm trees, Tree physiology, 33, 672-683, 2013.

Van Genuchten, M. T.: A closed-form equation for predicting the hydraulic conductivity of unsaturated soils, Soil science society of America journal, 44, 892-898, 1980.

865 Wang, W., Peng, C., Kneeshaw, D. D., Larocque, G. R., and Luo, Z.: Drought-induced tree mortality: ecological consequences, causes, and modeling, Environmental Reviews, 20, 109-121, 2012.

Xu, X., Medvigy, D., Powers, J. S., Becknell, J. M., and Guan, K.: Diversity in plant hydraulic traits explains seasonal and inter-annual variations of vegetation dynamics in seasonally dry tropical forests, New Phytologist, 212, 80-95, 2016.

Yang, Y., Saatchi, S. S., Xu, L., Yu, Y., Choi, S., Phillips, N., Kennedy, R., Keller, M., Knyazikhin, Y., and Myneni, R. B.: Postdrought decline of the Amazon carbon sink, Nature communications, 9, 1-9, 2018.

Yoshimura, K., Saiki, S.-T., Yazaki, K., Ogasa, M. Y., Shirai, M., Nakano, T., Yoshimura, J., and Ishida, A.: The dynamics of carbon stored in xylem sapwood to drought-induced hydraulic stress in mature trees, Scientific reports, 6, 24513, 2016.

Young, D. J., Stevens, J. T., Earles, J. M., Moore, J., Ellis, A., Jirka, A. L., and Latimer, A. M.: Long-term climate and competition explain forest mortality patterns under extreme drought, Ecology Letters, 20, 78-86, 2017.

875 Zhu, D., Peng, S., Ciais, P., Viovy, N., Druel, A., Kageyama, M., Krinner, G., Peylin, P., Ottlé, C., and Piao, S.: Improving the dynamics of Northern Hemisphere high-latitude vegetation in the ORCHIDEE ecosystem model, 2015.

Zhu, S.-D., Chen, Y.-J., Ye, Q., He, P.-C., Liu, H., Li, R.-H., Fu, P.-L., Jiang, G.-F., and Cao, K.-F.: Leaf turgor loss point is correlated with drought tolerance and leaf carbon economics traits, Tree Physiology, 38, 658-663, 2018. 
(a) ORCHIDEE-CAN

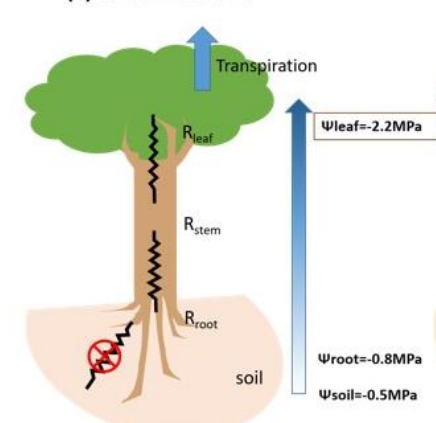

(b) ORCHIDEE-CAN-RS

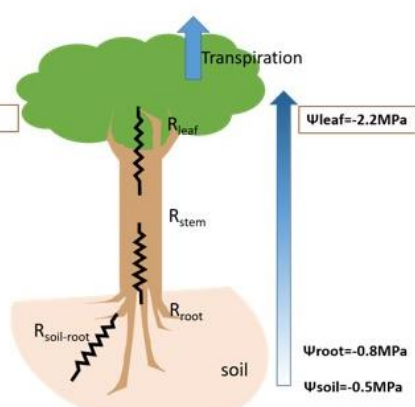

(c) ORCHIDEE-CAN-NHA

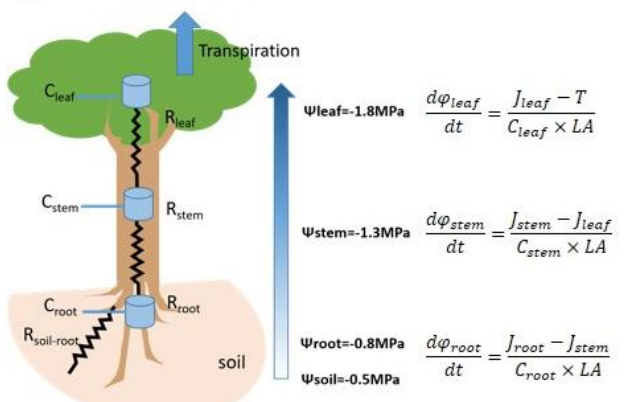

Figure 1 Schematic framework for hydraulic architecture in (a) ORCHIDEE-CAN, (b) ORCHIDEE-CAN-RS and (c) ORCHIDEE-CAN-NHA. The framed rectangles represent fixed values during the simulation. In ORCHIDEE-CAN and ORCHIDEE-CAN-RS, $R_{\text {leaf }}$ is related to leaf conductivity and leaf area. $R_{\text {stem }}$ is related to sapwood conductivity that can vary with cavitation and sapwood area. $R_{\text {root }}$ is related to fine root conductivity and root biomass. In ORCHIDEE-CAN-NHA, transport conductance of each organ is a function of their organ-specific water potential, maximum conductance and water potential when loss of $50 \%$ conductance occurred. $C_{\text {leaf }}, C_{\text {stem }}$ and $C_{\text {root }}$ represent water storage capacitance. $J_{\text {leaf }}, J_{\text {stem }}$ and $J_{\text {root }}$ 890 are vertical water transport to leaf, stem and root, respectively. $L A$ is total leaf area.

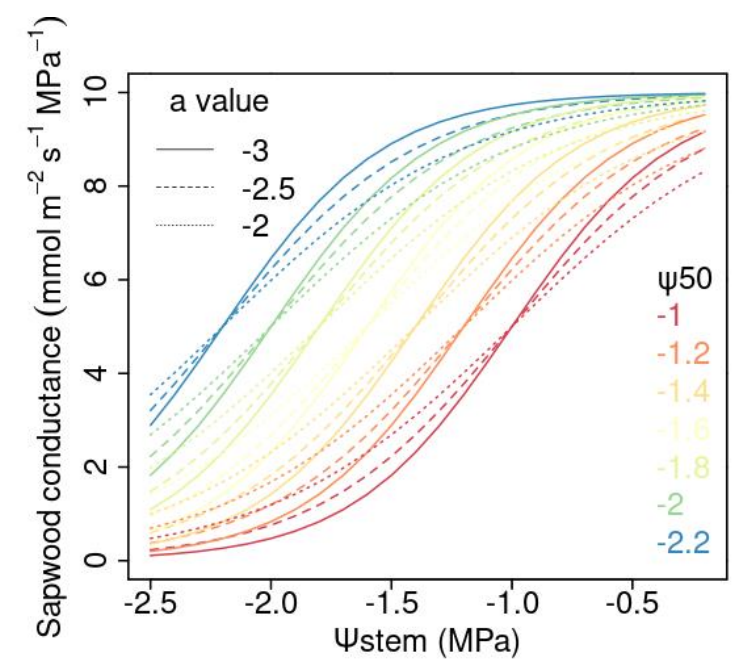

Figure 2 Sigmoidal relationship between stem sapwood conductance (normalized by total leaf area) and stem water potential. Line colors correspond to different $\Psi_{50}$ values. The line types (continuous, dashed and dotted line) denote different curvature parameters $\left(a_{\text {stem }}\right)$. 

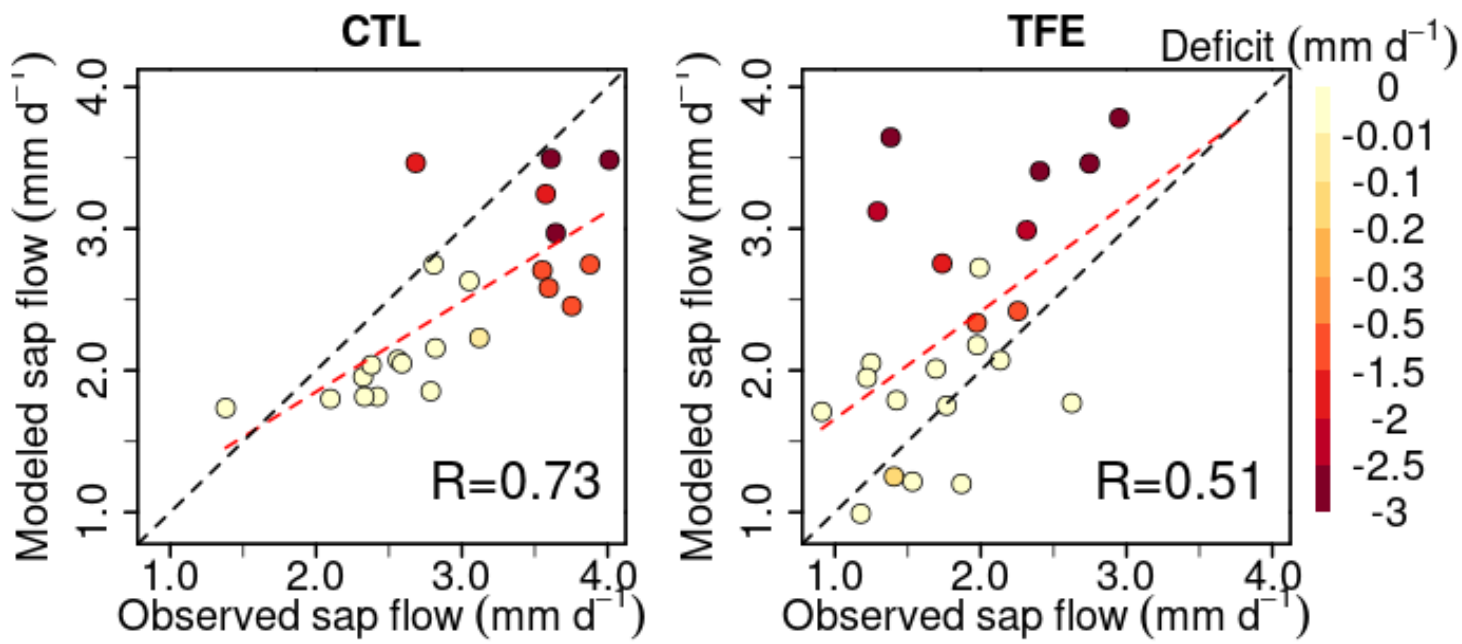

900 Figure 3 Modeled (ORCHIDEE-CAN-NHA) versus observed sap flow (monthly average values are displayed). The color of points indicates water deficit (negative difference between precipitation and evapotranspiration) with darker color meaning more severe water deficit. The black dashed line is the 1:1 line. The red dashed line is the best fit between modeled and observed sap flow.
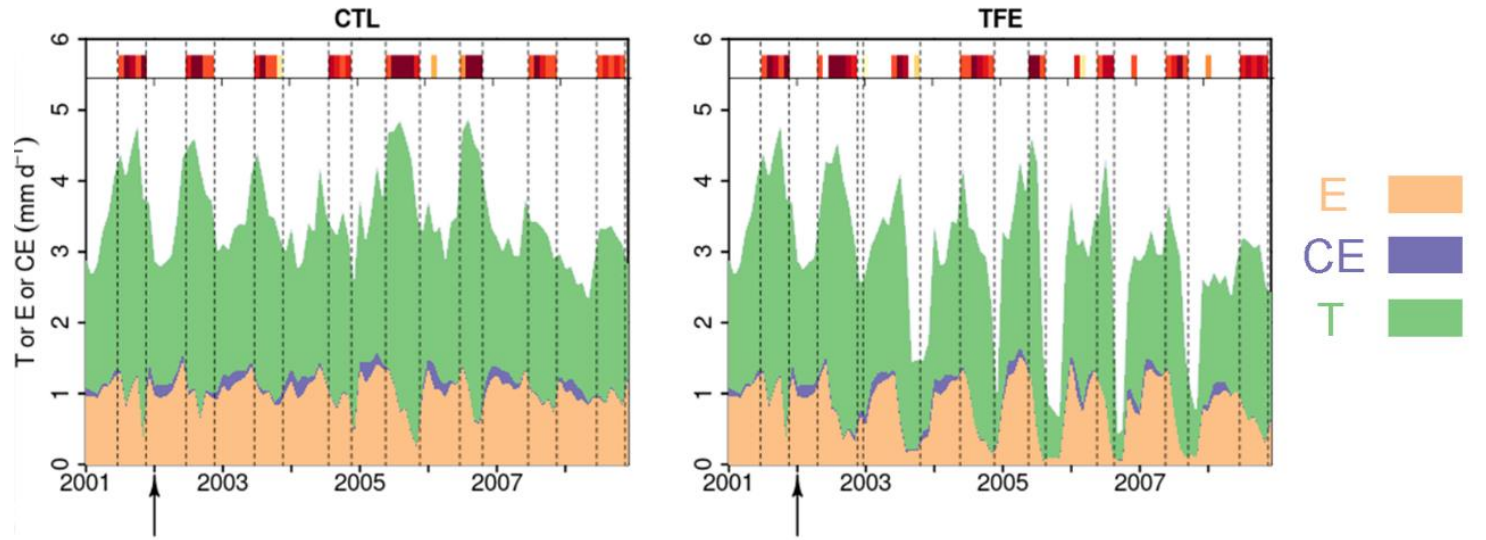

Figure 4 Modeled (ORCHIDEE-CAN-NHA) daily soil evaporation (E), canopy evaporation (CE) and transpiration (T) during 2001-2008. The arrows point to the start of TFE in the beginning of 2002. The inserted red shaded bars denote the periods with water deficits during the simulation period, following the same color scale as Fig. 3. 

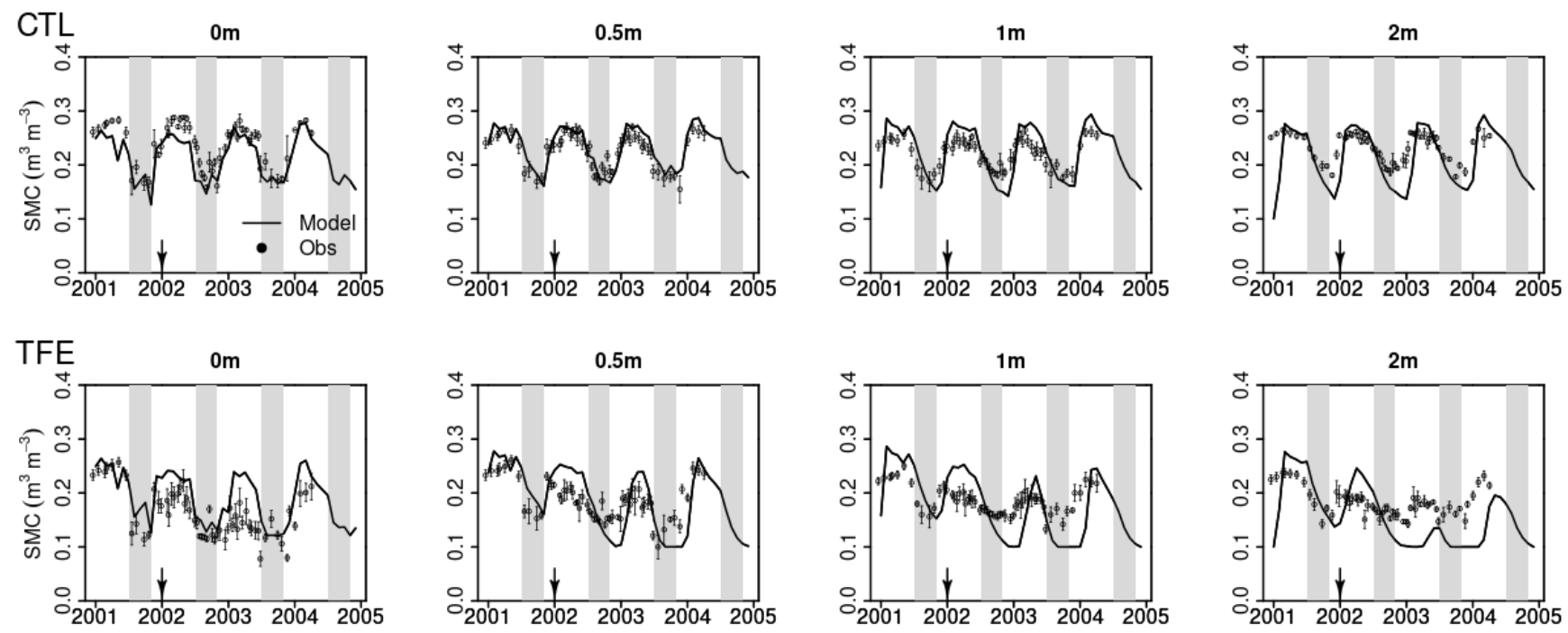

915 Figure 5 Modeled (ORCHIDEE-CAN-NHA, black line) versus observed (black dots) volumetric soil moisture content (SMC) at different depth. Due to the limited time duration of observation data, we only show the modeled SMC during 2001 to 2004. The grey shaded vertical area indicates the dry seasons from July to November.

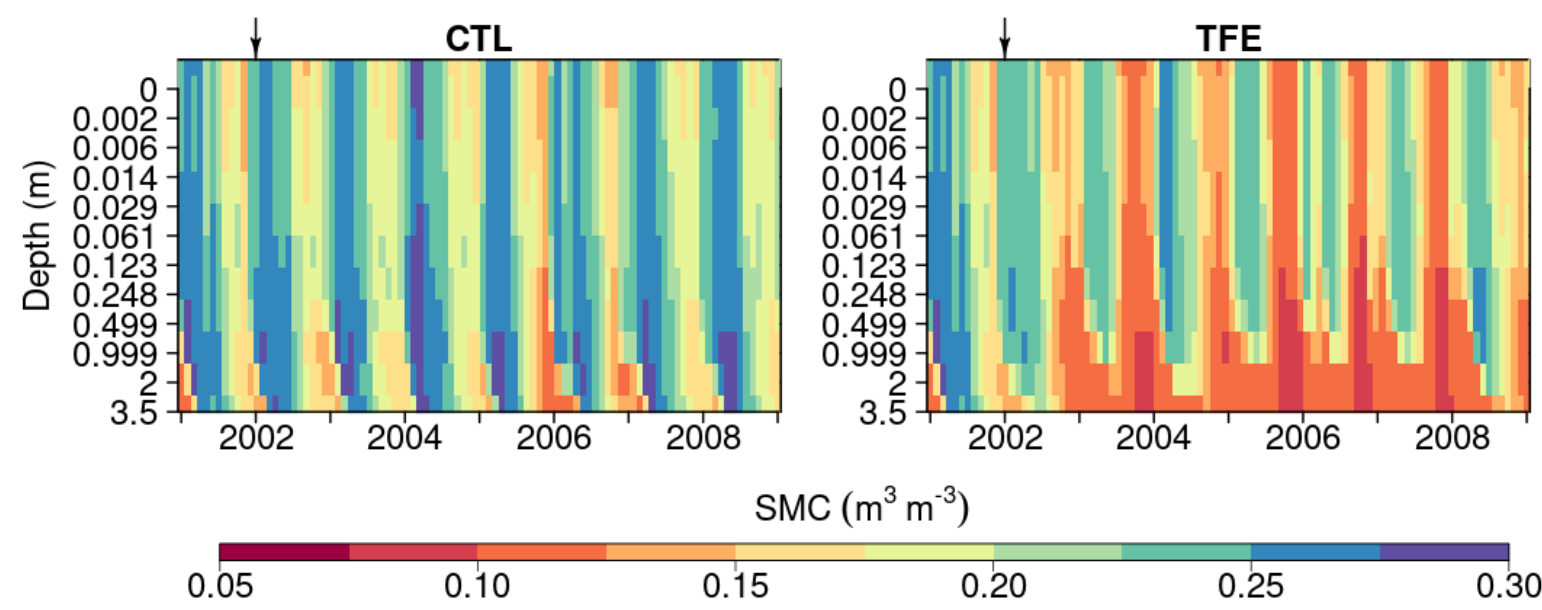

Figure 6 Soil moisture content simulated by ORCHIDEE-CAN-NHA during 2001 to 2008 under CTL and TFE. It should be noted the 12 soil layers have different thicknesses and here we show the SMC in same depth interval to present the change in $\mathrm{SMC}$ in top layers clearly. 

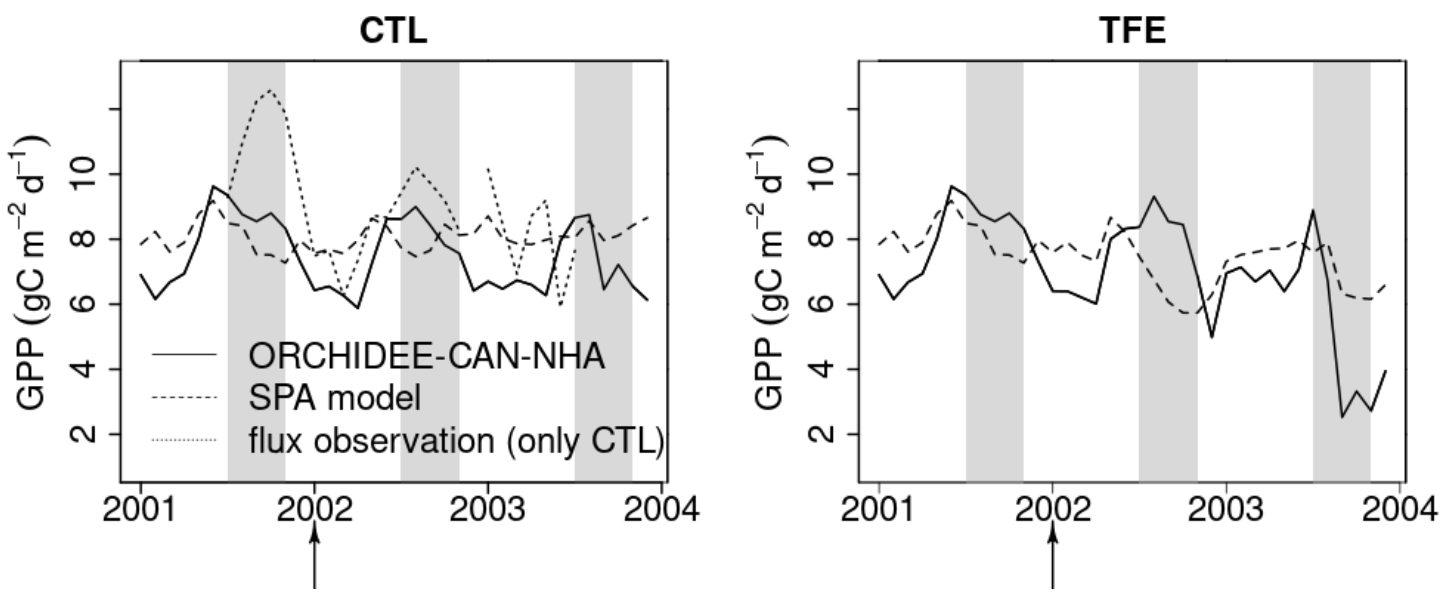

Figure 7 Modeled (ORCHIDEE-CAN-NHA) versus observed / modeled monthly mean GPP. The control model is compared to flux tower observations (Carswell et al., 2002). In the case of TFE, as no observation is available, the locally calibrated model SPA is used. Due to GPP flux observation is unrealistically low in the start of $2001\left(<5 \mathrm{gC} \mathrm{m}^{-2} \mathrm{~d}^{-1}\right)$, we only keep flux data after the mid of 2001. The grey shaded vertical area indicates the dry seasons from July to November.
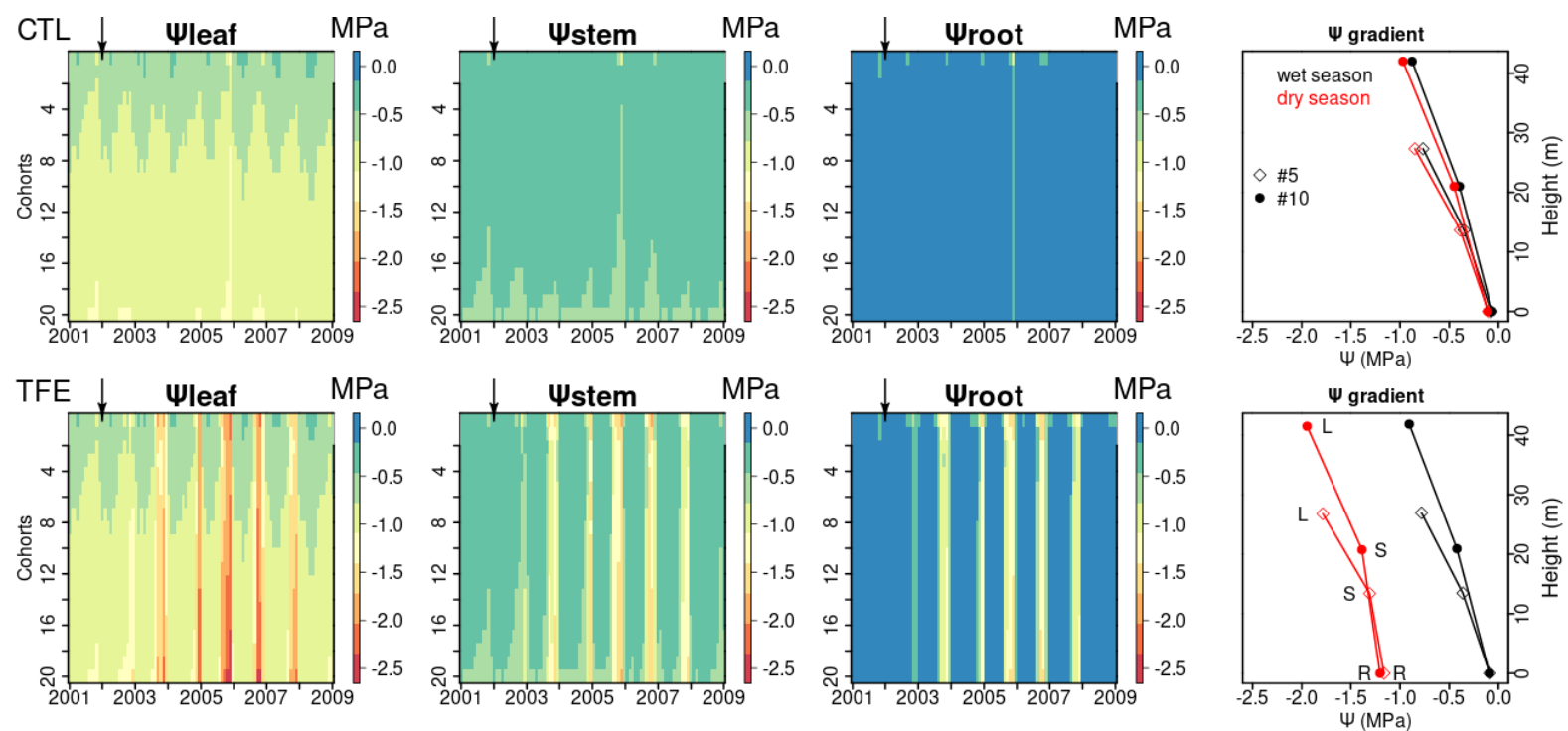

Figure $8 \Psi_{\text {leaf }}, \Psi_{\text {stem }}$, and $\Psi_{\text {root }}$ simulated by ORCHIDEE-CAN-NHA. Water potential gradients of two cohorts (\#5, \#10) are shown as an example (May 2005 as wet season, Nov 2005 as dry season). Here the cohort refers to circumference class (mean height of $\# 5$ and $\# 10$ are $19 \mathrm{~m}$, and $35 \mathrm{~m}$, respectively). The water potential gradient is composed by $\Psi_{\text {leaf }}$ (labeled as L), $\Psi_{\text {stem }}$ (labeled as S) and $\Psi_{\text {root }}$ (labeled as R). The heights of $\Psi_{\text {leaf }}$ and $\Psi_{\text {stem }}$ correspond to tree height and half of tree height, respectively. 

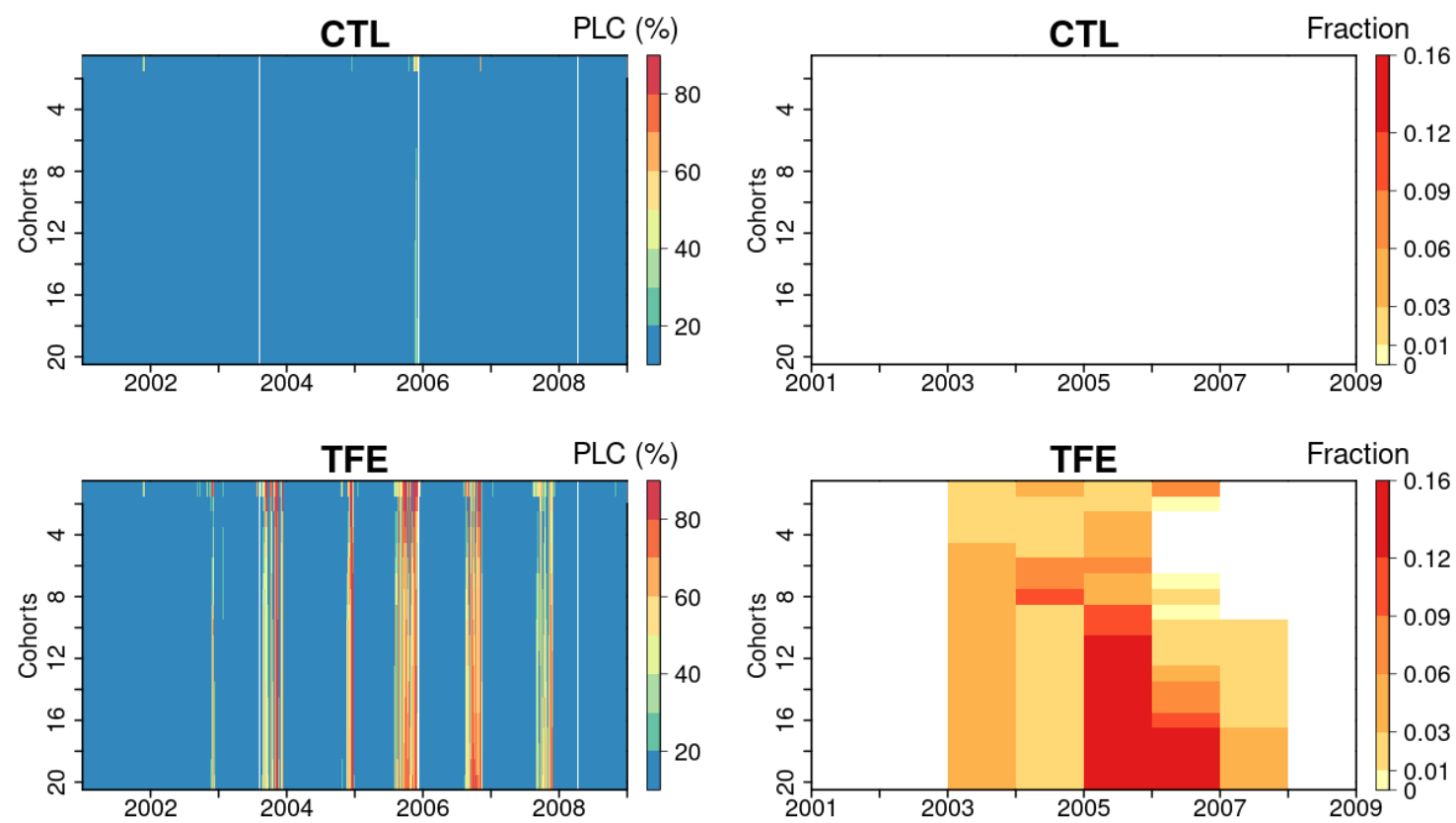

945 Figure 9 Percentage loss of daily stem conductance (PLC) (left) and tree mortality fraction simulated by ORCHIDEE-CANNHA (right). The vertical axis is for the index of 20 tree cohorts represented in the model, a larger index indicating taller trees (see Table S1 for tree height and diameter in each cohort). Tree mortality fraction per year is calculated by totaling the number of dead trees in each year and dividing it by the tree density in the first day of each year.

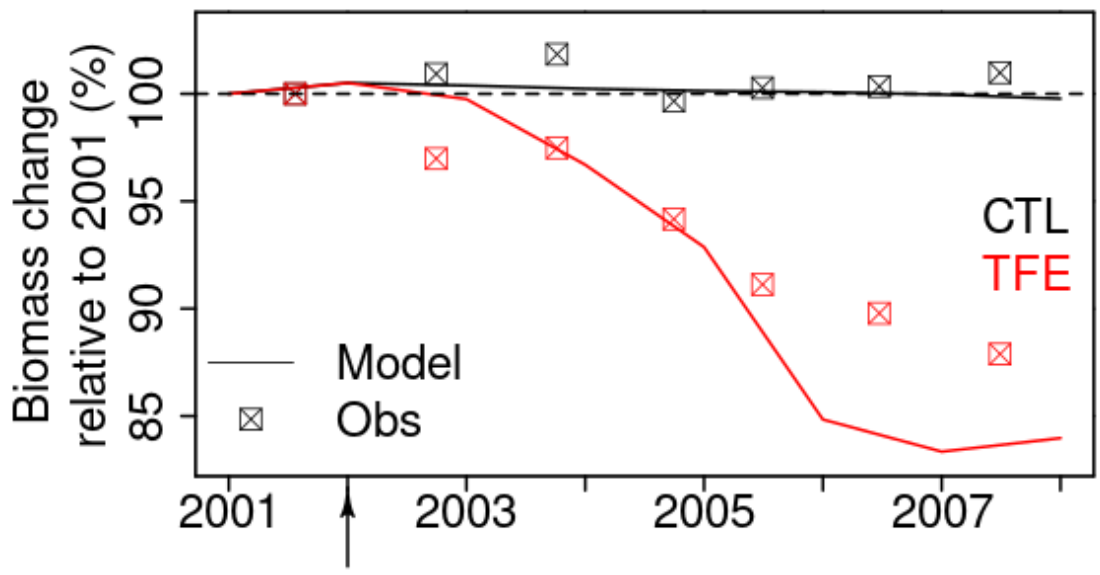

Figure 10 Tree biomass change simulated by model after mortality being triggered. The squares in the plot denote the observation. Biomass change relative to 2001 is calculated by dividing biomass during 2002-2008 by biomass in 2001 . 
CTL

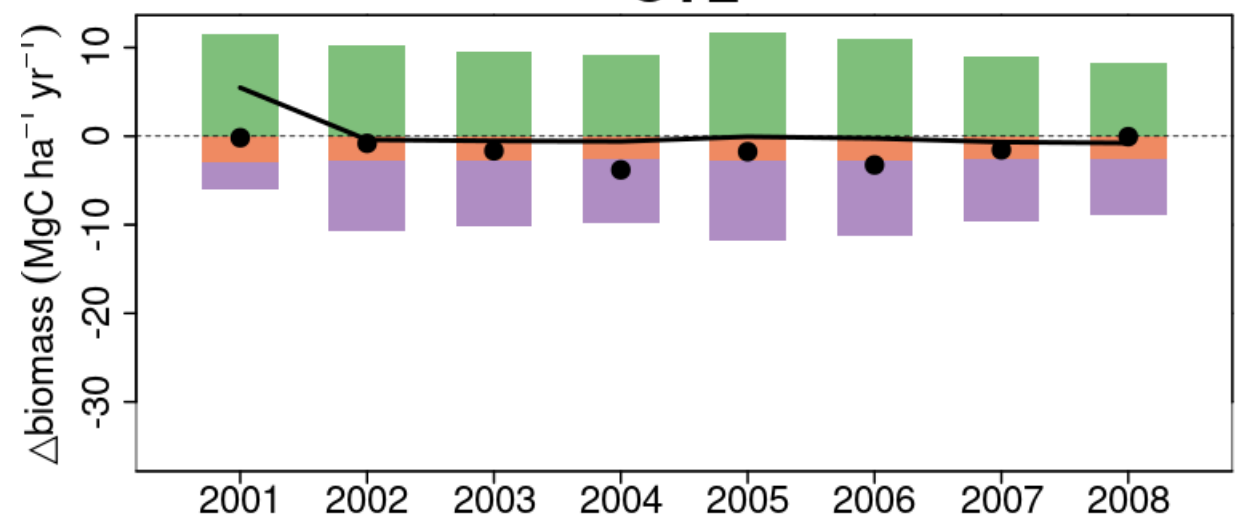

\section{TFE}

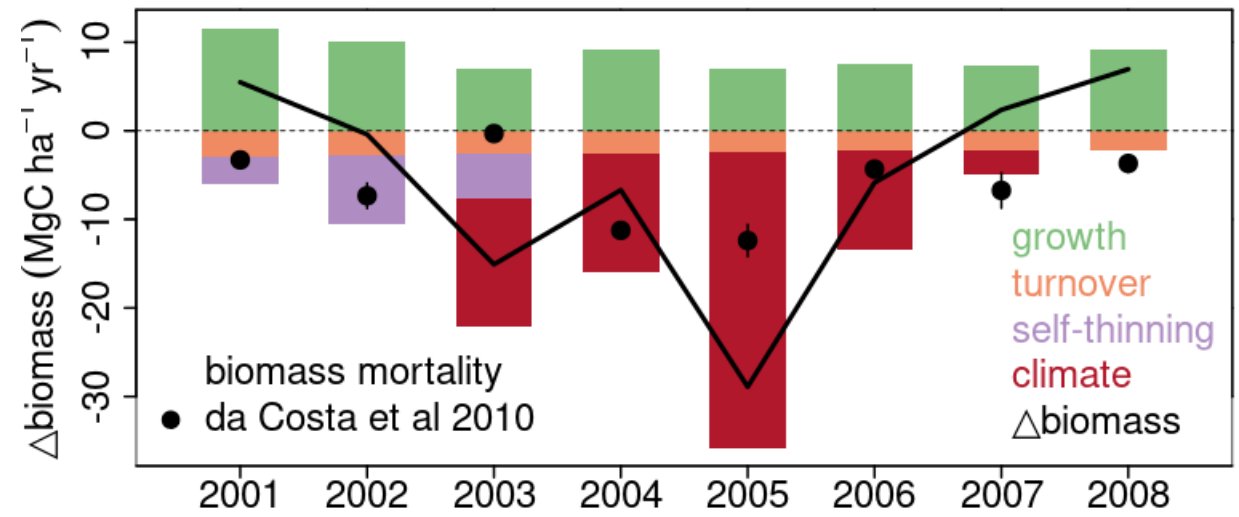

Figure 11 Simulated components of biomass change and observed net biomass change during 2001 to 2008 . The observed net biomass change data in each year from da Costa et al (2010) is plotted as black dot. The black line shows the net change of simulated biomass by ORCHIDEE-CAN-NHA. 

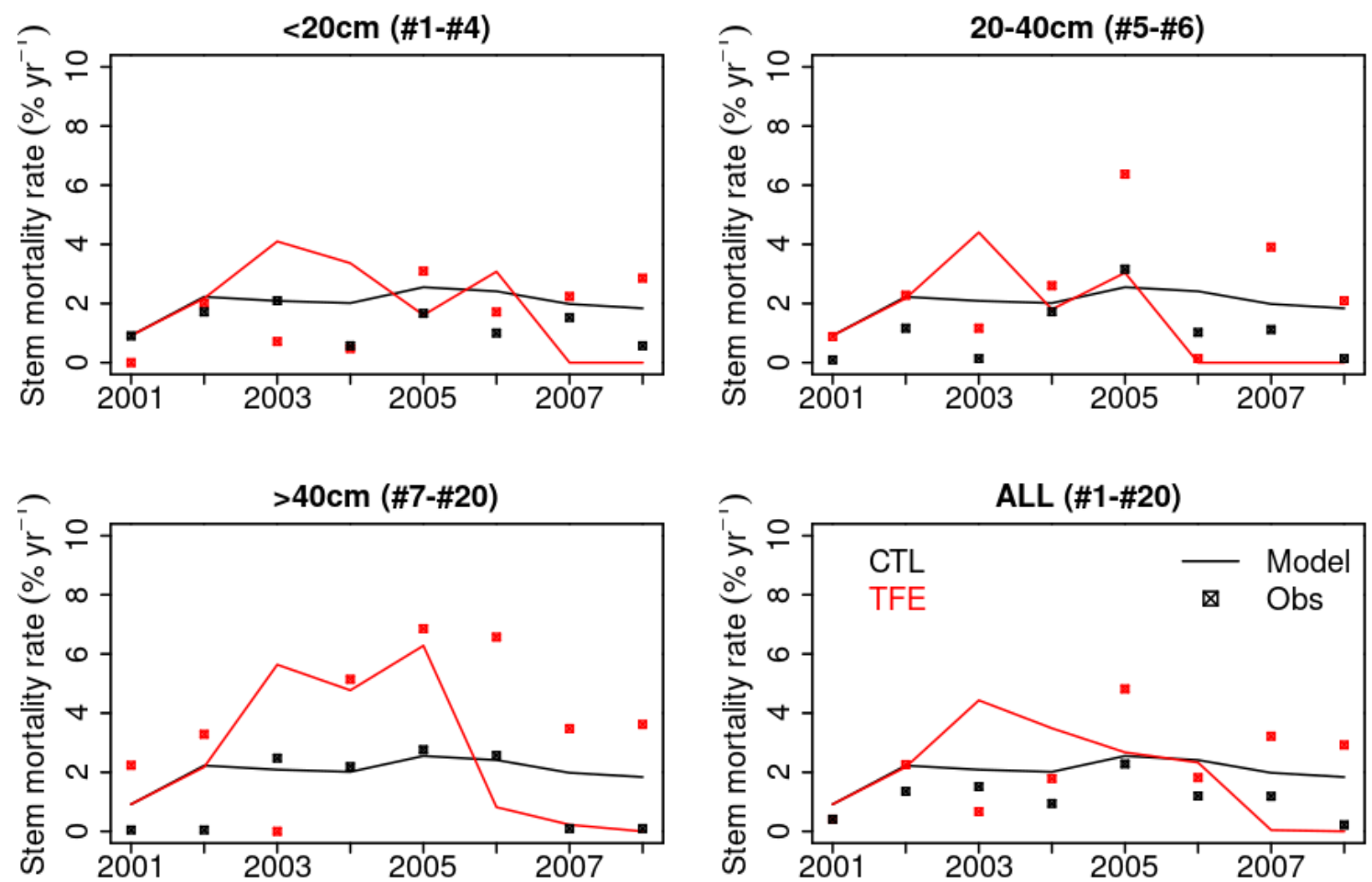

Figure 12 Annual stem mortality rates during the study period (2001 - 2008). All 20 cohorts have been aggregated to three

classes according to DBH $(<20 \mathrm{~cm}, 20-40 \mathrm{~cm},>40 \mathrm{~cm})$. The value in bracket in title of each panel corresponds to the No. of cohorts falling in the class. 